\title{
Zinc Complexes with 1,3-Diketones as Activators for Sulfur Vulcanization of Styrene-Butadiene Elastomer Filled with Carbon Black
}

\author{
Magdalena Maciejewska *(D), Anna Sowińska *(1) and Agata Grocholewicz \\ Department of Chemistry, Institute of Polymer and Dye Technology, Lodz University of Technology, \\ Stefanowskiego Street 12/16, 90-924 Lodz, Poland; 233551@edu.p.lodz.pl \\ * Correspondence: magdalena.maciejewska@p.lodz.pl (M.M.); anna.sowinska@p.lodz.pl (A.S.)
}

check for

updates

Citation: Maciejewska, M.;

Sowińska, A.; Grocholewicz, A. Zinc

Complexes with 1,3-Diketones as

Activators for Sulfur Vulcanization of Styrene-Butadiene Elastomer Filled with Carbon Black. Materials 2021, 14, 3804. https://doi.org/10.3390/ ma14143804

Academic Editor: Klaus

Werner Stöckelhuber

Received: 14 June 2021

Accepted: 5 July 2021

Published: 7 July 2021

Publisher's Note: MDPI stays neutral with regard to jurisdictional claims in published maps and institutional affiliations.

Copyright: (c) 2021 by the authors. Licensee MDPI, Basel, Switzerland. This article is an open access article distributed under the terms and conditions of the Creative Commons Attribution (CC BY) license (https:/ / creativecommons.org/licenses/by/ $4.0 /)$.
Abstract: Zinc oxide nanoparticles ( $\mathrm{N}-\mathrm{ZnO})$ and zinc complexes with 1,3-diketones of different structures were applied instead of microsized zinc oxide $(\mathrm{M}-\mathrm{ZnO})$ to activate the sulfur vulcanization of styrene-butadiene rubber (SBR). The influence of vulcanization activators on the cure characteristics of rubber compounds, as well as crosslink density and functional properties of SBR vulcanizates, such as tensile properties, hardness, damping behavior, thermal stability and resistance to thermooxidative aging was explored. Applying $\mathrm{N}-\mathrm{ZnO}$ allowed to reduce the content of zinc by $40 \%$ compared to $\mathrm{M}-\mathrm{ZnO}$ without detrimental influence on the cure characteristic and performance of SBR composites. The activity of zinc complexes in vulcanization seems to strongly depend on their structure, i.e., availability of zinc to react with curatives. The lower the steric hindrance of the substituents and thus the better the availability of zinc ions, the greater was the activity of the zinc complex and consequently the higher the crosslink density of the vulcanizates. Zinc complexes had no detrimental effect on the time and temperature of SBR vulcanization. Despite lower crosslink density, most vulcanizates with zinc complexes demonstrated similar or improved functional properties in comparison with SBR containing M-ZnO. Most importantly, zinc complexes allowed the content of zinc in SBR compounds to be reduced by approximately $90 \%$ compared to $\mathrm{M}-\mathrm{ZnO}$.

Keywords: zinc complexes; 1,3-diketones; vulcanization; cure characteristics; mechanical properties

\section{Introduction}

Sulfur vulcanization is the oldest and one of the most widely exploited method for the crosslinking of rubbers having unsaturated double bonds in their macromolecules, such as natural rubber (NR) and synthetic rubbers, e.g., styrene-butadiene rubber (SBR) [1]. Standard sulfur crosslinking system consists of elementary sulfur as crosslinking agent, vulcanization accelerators and activators. Additionally, many sulfur donors can be applied as curatives instead of elementary sulfur. Even though, sulfur vulcanization has been known for over 150 years, the chemistry and mechanism of sulfur crosslinking is still quite incomprehensible. It is generally accepted that when rubber compound is heated in the presence of accelerators and activators, sulfur decomposes into sulfur fragments which react with the functional groups of the rubber to create crosslinks [2]. Interaction of the accelerators and activators makes the mechanism of vulcanization more complicated due to the fact that each of reactants affects the reactivity of the other, and their interactions in turn affect the curing mechanism. Many research papers on vulcanization mechanisms have been published over the years, focusing mainly on the effect of accelerators and activators on the course of crosslinking reactions [3-6]. This confirms the important role of these ingredients in the rubber technology, since applying vulcanization accelerators and activators results in an effective and rapid crosslinking of rubber compounds. Otherwise, sulfur reacts very slowly with elastomer chains and binds to them mainly in the form of cyclic side structures, not in the form of sulfur crosslinks [2]. Accelerators and activators 
affect the parameters of vulcanization, such as temperature and time, as well as the safety of rubbers processing. Furthermore, they increase the crosslinks density and improve the yield of sulfur needed to form crosslinks [7]. The most widely used activator is zinc oxide ( $\mathrm{ZnO})$. Apart from the activation of vulcanization, $\mathrm{ZnO}$ has been reported to increase the crosslinking efficiency and to reduce the reversion during vulcanization. In addition, incorporation of $\mathrm{ZnO}$ slightly increases both the vulcanization time and the scorch time, which is crucial for the processing security [8]. Moreover, $\mathrm{ZnO}$ is known as a very effective and commonly used curing agent for carboxylated elastomers, leading to labile ionic crosslinks in the elastomeric network. It allows to obtain vulcanizates with high tensile strength, tear resistance, hysteresis and hardness [9]. $\mathrm{ZnO}$ is also a curing agent of chloroprene rubbers [10] and chlorosulfonated polyethylene [11]. Furthermore, $\mathrm{ZnO}$ can act as a white colorant or filler in polymer composites, especially those intended for products with increased heat conductivity [12]. Unfortunately, despite crucial role and wide applications in elastomer technology, $\mathrm{ZnO}$ has been classified as being very toxic to aquatic life by European Union Regulation (EC) No 1272/2008 on classification, labelling and packaging of substances and mixtures. Following the precaution recommended for $\mathrm{ZnO}$ in this Regulation defined as "P273: Avoid release to the environment", the concentration of $\mathrm{ZnO}$ in rubber compounds, especially those used in aquatic environments, must be reduced to below $2.5 \mathrm{wt}$.\%. The complete elimination of $\mathrm{ZnO}$ from rubber compounds is also highly recommended [13]. Hence, scientists and technologists have made efforts to reduce the amount of $\mathrm{ZnO}$ in rubber products or replace it with zinc compounds with a lower content of zinc ions.

The first approach to reduce the level of zinc in elastomer composites was replacing the commercially used microsized $\mathrm{ZnO}$ with more active forms of $\mathrm{ZnO}$, which demonstrated high surface area and/or very small particle size, i.e., active $\mathrm{ZnO}$ or nanosized $\mathrm{ZnO}$ [13-17]. Sahoo et al. [18] applied $\mathrm{ZnO}$ nanoparticles with an average size of $50 \mathrm{~nm}$ to activate sulfur vulcanization of NR and acrylonitrile-butadiene rubber (NBR). Owing to the higher surface area and uniform dispersion of nanoparticles in the rubber matrix, the reactivity of $\mathrm{ZnO}$ with the curatives was improved compared to microsized $\mathrm{ZnO}$, resulting in the higher crosslinking degree of the elastomer [18]. Beneficial influence of nanosized $\mathrm{ZnO}$ on the cure characteristics and performance of NR composites was confirmed by Panampilly et al. [19] and Roy et al. [20]. Applying N-ZnO alternatively to $\mathrm{M}-\mathrm{ZnO}$ enabled to reduce the level of $\mathrm{ZnO}$ to 0.5 parts per hundred of rubber (phr). Thus, reducing the size of particles and increasing the specific surface area of $\mathrm{ZnO}$ was proven to be an effective way to decrease the level of zinc in rubber products. However, to ensure the high activity of $\mathrm{ZnO}$ in the vulcanization process and the required performance of the vulcanizates, it was necessary to obtain a homogeneous dispersion of nanoparticles in the elastomer matrix, which is technologically difficult due to their susceptibility to agglomeration. To overcome this disadvantage, and thus obtain a homogeneous dispersion of $\mathrm{ZnO}$ nanoparticles in the elastomer matrix, it is often necessary to use additional additives that act as dispersing agents of $\mathrm{N}-\mathrm{ZnO}$. The use of crown ethers [14], alkylammonium salts or ionic liquids [21] was reported to effectively improve the dispersion of $\mathrm{N}-\mathrm{ZnO}$ in an elastomer matrix and, consequently, its activity in the vulcanization process. However, these additives also affect the final properties of the vulcanizates, e.g., they deteriorate the thermal stability $[22,23]$.

Next approach to reduce the amount of zinc in rubber compounds was replacing $\mathrm{ZnO}$ with more chemically active zinc, in the form of reactive organic zinc complexes, in which the availability of zinc to react with curatives is better than in $\mathrm{ZnO}$ crystals. Hence, zinc stearate, zinc 2-ethylhexanoate and zinc m-glycerolate were employed instead of $\mathrm{ZnO}$ to activate the sulfur vulcanization of ethylene-propylene-diene terpolymer (EPDM) and SBR rubber [24]. Zinc m-glycerolate with the highest amount of zinc per $1 \mathrm{~g}$ showed the highest activity in the vulcanization. However, no reduction in the zinc amount was provided compared to rubber compounds cured with $\mathrm{ZnO}$. Helaly et al. [25] applied zinc stearate to activate sulfur vulcanization of NR compounds filled with different fillers, e.g., carbon black, $\mathrm{CaCO}_{3}$, hydrated silicon dioxide and talc. Zinc stearate allowed for partial 
and complete replacement of conventional $\mathrm{ZnO}$ and stearic acid with improvement of the physico-mechanical properties of NR composites. However, in the case of unfilled rubber compounds, significantly lower torque increment during rheometric tests was obtained, suggesting significantly lower crosslinking degree compared to the elastomer cured with $\mathrm{ZnO} /$ stearic acid system. Furthermore, Maciejewska et al. [26], applied organic zinc salts and complexes, such as zinc acetylacetonate, zinc gluconate and zinc ricinoleate, as activators for sulfur vulcanization of SBR in order to reduce the level of zinc in rubber compounds. Organic zinc activators efficiently activated the vulcanization without detrimental effect on the optimal time and temperature of this process. However, due to a 70-90\% lower content of zinc, SBR vulcanizates exhibited lower crosslink density compared to $\mathrm{ZnO}$-containing rubber. On the other hand, reduction of the crosslink density did not worsen mechanical properties of the vulcanizates in both static and dynamic conditions. The most effective zinc activator was zinc gluconate. Moresco et al. [27] reduced the level of zinc in NR composites by $75 \%$ compared to the standard formulation with $5 \mathrm{phr}$ of $\mathrm{ZnO}$. Vegetable oil with aromatic zinc carboxylate were used as vulcanization activators instead of $\mathrm{ZnO}$ and stearic acid without affecting the mechanical performance of the elastomer composites. Moreover, the vegetable oil acted both as an activator and a lubricant of natural origin. Zachnet et al. [28] employed an activator derived from chemically modified sugar cane bagasse. It contained water, zinc carboxylate, stearic acid and lignin. The overall zinc content in this activator was $25.6 \%$. Regarding vulcanization kinetics, this activator was a good alternative to $\mathrm{ZnO} /$ stearic acid system, which allowed to reduce the level of zinc by approximately $75 \%$ without detrimental influence on the crosslink density of the vulcanizates and their dynamic mechanical properties. NR composites with improved thermal stability were obtained compared to those containing $5 \mathrm{phr}$ of $\mathrm{ZnO}$.

The last approach to reduce the content of zinc in elastomer composites was incorporation of zinc ions into the structure of mineral layered fillers, e.g., montmorillonite (MMT) [29] and layered double hydroxides (LDHs) [30]. For example, Heideman et al. [29] developed zinc loaded clay (Zn-clay) consisted of MMT into which zinc ions were incorporated via the ion exchange reaction. Such a modified MMT was employed to activate the sulfur vulcanization of SBR alternatively to $\mathrm{ZnO}$. Despite significantly lower content of zinc, Zn-clay allowed to achieve comparable curing characteristics, crosslinking degree and performance to the SBR composites cured with ZnO. Das et al. [30], prepared Zn-containing LDH filler, which delivered both zinc ions and stearate anions to activate the sulfur vulcanization of various unsaturated rubbers. The organo-modified LDH allowed to replace the $\mathrm{ZnO}$ and stearic acid in rubber compounds leading to significant reduction of zinc level in the final elastomer composites, without deterioration of their crosslinking degree and mechanical properties. The content of zinc was approximately 10 times lower compared to conventionally prepared composites. In addition, transparent sulfur-crosslinked elastomer composites were achieved, which is impossible when $\mathrm{ZnO}$ is used as a standard vulcanization activator.

To summarize, taking into account the current state of the natural environment, the topic of zinc reduction in rubber products is still very relevant. Despite the abovepresented method of reducing the amount of zinc in the elastomer technology and the consequently developed vulcanization activators, it is still justified to search for new compounds that can successfully activate vulcanization while enabling the greatest possible reduction of the amount of zinc in rubber products. Thus, in this work, we applied zinc complexes with 1,3-diketones to activate the sulfur vulcanization of SBR elastomer filled with carbon black. This study is a continuation of our previous work on the use of zinc complexes to activate sulfur vulcanization of unfilled NBR compounds [31]. However, since SBR composites filled with carbon black are widely used in industry, e.g., in the automotive industry, it is justified to study the activity of zinc complexes with 1,3-diketones as vulcanization activators of such composites. Moreover, it is well known that the filler can influence the activity of the crosslinking system [32-34]. Therefore, the effect of filler on the efficiency of zinc complexes with 1,3-diketones as vulcanization activators should 
also be explored. As was already mentioned, zinc complexes with 1,3-diketones were previously applied to activate the sulfur vulcanization of unfilled NBR and the application of vulcanization activators based on organic zinc complexes alternatively to $\mathrm{ZnO}$ is known from the literature, but the proposed zinc complexes with aliphatic-aromatic 1,3-diketones allows to achieve the most significant reduction of the zinc level (by approximately $90 \%$ ) in rubber composites compared to other organic zinc activators reported in the literature, without significantly lowering the crosslink density and most importantly with beneficial effect on the mechanical performance of the vulcanizates and their resistance to prolonged thermo-oxidation.

\section{Materials and Methods}

\subsection{Materials}

Styrene-butadiene rubber (SBR, KER 1500 type) was provided by Synthos SA (Oswiecim, Poland). It contains $23.5 \mathrm{wt} . \%$ of bonded styrene and exhibits the Mooney viscosity of ML1 $+4\left(100^{\circ} \mathrm{C}\right)$ : 50 . A conventional curing system containing sulfur as curing agent (Siarkopol, Tarnobrzeg, Poland) in the presence of two vulcanization accelerators, i.e., 2-mercaptobenzothiazole (MBT) and N-cyclohexyl-2-benzothiazolesulfenamide (CBS) (Sigma-Aldrich, Schelldorf, Germany) was applied for all rubber compounds. Microsized zinc oxide $(\mathrm{M}-\mathrm{ZnO})$ with a specific surface area of $10 \mathrm{~m}^{2} \cdot \mathrm{g}^{-1}$ (Huta Bedzin, Bedzin, Poland) was applied as standard activator only for the reference rubber compound. Zinc oxide nanopowder $(\mathrm{N}-\mathrm{ZnO})$ with a specific surface area of $25 \mathrm{~m}^{2} \mathrm{~g}^{-1}$ (Sigma-Aldrich, Schelldorf, Germany) and zinc complexes with 1-3-diketones were used as alternative vulcanization activators to reduce the content of zinc in rubber compounds as compared to $\mathrm{M}-\mathrm{ZnO}$. The procedure for the synthesis of zinc complexes from commercially available 1,3-diketones has been previously published [31]. Carbon black N550 supplied by Konimpex (Konin, Poland) was used as a filler. It was characterized by the surface area of $40 \mathrm{~m}^{2} \cdot \mathrm{g}^{-1}$ and $\mathrm{pH}$ in the range of $7-10$. The structures of the zinc complexes employed as vulcanization activators are shown in Figures 1-4.

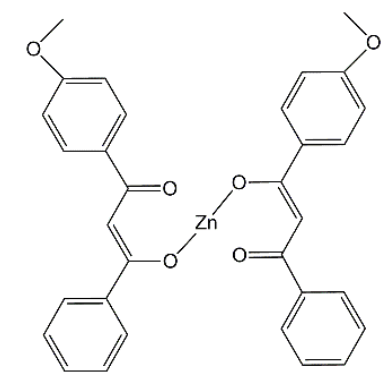

Figure 1. Structure of zinc 1-(4'-methoxyphenyl)-3-phenylpropane-1,3-dione (MBPP-Zn).

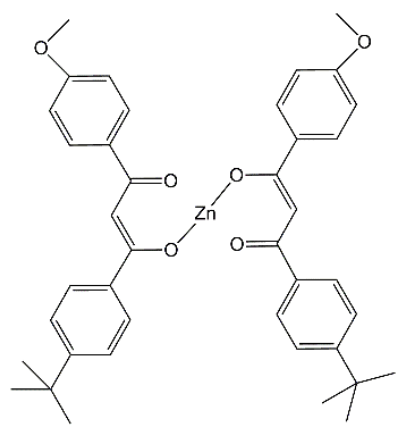

Figure 2. Structure of zinc 1-(4'-t-butylphenyl)-3-(4"-methoxyphenyl)propane-1,3-dione (tBuMBPP$\mathrm{Zn})$. 


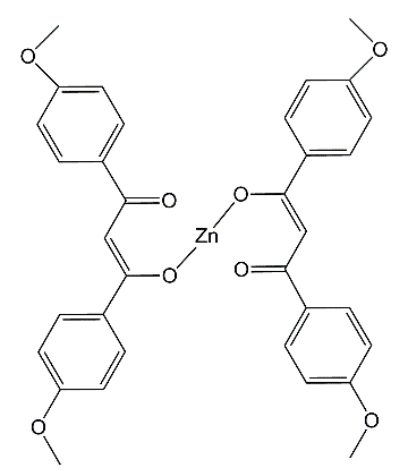

Figure 3. Structure of zinc 1,3-bis-(4' methoxyphenyl)propane-1,3-dione (MMBPP-Zn).

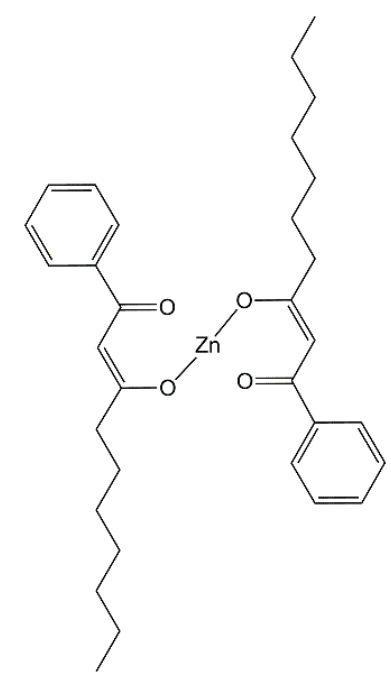

Figure 4. Structure of zinc 1-heptyl-3-phenylpropane-1,3-dione (HeBPP-Zn).

\subsection{Preparation and Characterization of SBR Compounds}

SBR compounds were manufactured using a laboratory rolling mill (David Bridge \& Co, Rochdale, UK) in a two-step procedure. The first step was to prepare the masterbatch, which consisted of the SBR rubber, curative (sulfur), accelerators (MBT and CBS) and filler carbon black (CB). The time for preparing a masterbatch including the mastication of rubber was approximately $15 \mathrm{~min}$. The masterbatch was then divided into seven pieces of the same weight. Next, the proper activator ( $\mathrm{M}-\mathrm{ZnO}, \mathrm{N}-\mathrm{ZnO}$ or zinc complex, alternatively) was added to each of these pieces and mixed up for additional $5 \mathrm{~min}$. The general formulations of SBR compounds are listed in Table 1 in parts per hundred of rubber (phr).

Since N-ZnO and zinc complexes were applied to reduce the content of zinc in SBR compounds, the amount of zinc ions introduced into the rubber in the form of $\mathrm{M}-\mathrm{ZnO}, \mathrm{N}$ $\mathrm{ZnO}$ and particular zinc complexes with 1,3-diketones was calculated using their molecular masses and is given in Table 2. It should be noted that compared to $\mathrm{M}-\mathrm{ZnO}$, the content of zinc in SBR compounds was by approximately $40 \%$ and $90 \%$ smaller for $\mathrm{N}-\mathrm{ZnO}$ and zinc complexes, respectively.

Electrically heated hydraulic press was employed to vulcanize the SBR compounds at a temperature of $160^{\circ} \mathrm{C}$ and a pressure of $15 \mathrm{MPa}$. All SBR compounds were cured using the optimal vulcanization times determined during rheometric tests. The cure characteristics of $\mathrm{SBR}$ compounds were examined at $160^{\circ} \mathrm{C}$ using the procedure described in ISO 6502 [35]. A rotorless D-RPA 3000 (MonTech, Buchen, Germany) rheometer was applied for these measurements. The optimal vulcanization time $\left(t_{90}\right)$ was established using the Equation (1), where $\Delta S$ is the torque increase during rheometric measurement, 
calculated as the difference between the maximum $\left(S_{\max }\right)$ and minimum torque $\left(S_{\min }\right)$, respectively. The scorch time $\left(t_{02}\right)$ was determined analogously to $t_{90}$.

$$
S_{90}=0.9 \Delta S+S_{\min }
$$

The influence of vulcanization activators on the temperature and the enthalpy of SBR compounds curing reactions was examined with a DSC1 (Mettler Toledo, Greifensee, Switzerland) differential scanning calorimeter (Mettler Toledo, Greifensee, Switzerland) equipped with a STAR ${ }^{\mathrm{e}}$ software (Version 10, 2010, Mettler Toledo, Greifensee, Switzerland). The DSC measurements were carried out in the temperature range of $-100-250{ }^{\circ} \mathrm{C}$, with a heating rate of $10^{\circ} \mathrm{C} / \mathrm{min}$. The onset curing temperature was determined following the ISO 11357-1 [36] standard using the STAR ${ }^{\mathrm{e}}$ software.

Table 1. General formulations of the styrene-butadiene-rubber (SBR) compounds, parts per hundred of rubber (phr); MBT, 2-mercaptobenzothizole; CBS, N-cyclohexyl-2-benzothiazolesulfenamide; $\mathrm{M}-\mathrm{ZnO}$, microsized zinc oxide; $\mathrm{N}-\mathrm{ZnO}$, zinc oxide nanopowder; $\mathrm{CB}$, carbon black.

\begin{tabular}{cccc}
\hline Ingredient & $\begin{array}{c}\text { Reference } \\
\text { Sample }\end{array}$ & $\begin{array}{c}\text { SBR Compound } \\
\text { with N-ZnO }\end{array}$ & $\begin{array}{c}\text { SBR Compound with } \\
\text { Zinc Complexes } \mathbf{~}^{\text {inc }}\end{array}$ \\
\hline SBR & 100 & 100 & 100 \\
Sulfur & 2 & 2 & 2 \\
CBS & 1 & 1 & 1 \\
MBT & 1 & 1 & 1 \\
CB & 30 & 30 & 30 \\
M-ZnO & 5 & - & - \\
N-ZnO & - & 3 & 3 \\
Zinc complex & - & 30 & - \\
\hline
\end{tabular}

${ }^{1}$ One of the rubber compounds contained a mixture of $\mathrm{N}-\mathrm{ZnO}(1.5 \mathrm{phr})$ and MBPP-Zn (1.5 phr).

Table 2. Amount of zinc in SBR compounds containing different vulcanization activators.

\begin{tabular}{ccc}
\hline Activator & $\begin{array}{c}\text { Amount of Zinc in Activator } \\
\text { (mmolg) }\end{array}$ & $\begin{array}{c}\text { Amount of Zinc in SBR Compound } \\
\text { (mmol/100 g of SBR) }\end{array}$ \\
\hline M-ZnO & 12.3 & 61.5 \\
N-ZnO & 12.3 & 36.9 \\
MBPP-Zn & 1.7 & 5.1 \\
tBuMBPP-Zn & 2.2 & 6.6 \\
MMBPP-Zn & 1.6 & 4.8 \\
HeBPP-Zn & 1.8 & 5.4 \\
\hline
\end{tabular}

Fourier transform infrared spectroscopy (FTIR) absorbance spectra were recorded in the range of wavenumbers from 4000 to $400 \mathrm{~cm}^{-1}$ with 64 scans. The analysis was carried out employing Thermo Scientific Nicolet 6700 (Thermo Fisher Scientific, Waltham, MA, USA) FTIR spectrometer equipped with OMNIC 8.2 software $(8.2,2010$, Thermo Fisher Scientific, Waltham, MA, USA). ATR (Attenuated Total Reflectance) mode with a single reflection diamond ATR crystal was applied for all measurements.

The crosslink density of SBR vulcanizates with different vulcanization activators was determined based on solvent-swelling measurements, which were performed according to the standard ISO 1817 [37]. Four samples with a mass in the range of 20-50 mg were tested for each vulcanizate. Toluene (Chempur, Piekary Slaskie, Poland) was chosen as a solvent. Next, the Flory-Rehner equation [38] was applied to calculate the crosslink density of the vulcanizates with the Huggins parameter of SBR-toluene interaction given by Equation (2), where $V_{r}$ is the volume fraction of elastomer in swollen gel [39].

$$
\chi=0.37+0.56 V_{r}
$$


The mechanical properties of the vulcanizates were tested in the static and dynamic conditions. The static mechanical properties were investigated using a universal testing machine Zwick Roell 1435 (Ulm, Germany) following the procedure described in the ISO 37 [40]. Dynamic mechanical measurements were carried out in tension mode with a dynamic-mechanical analyzer DMA/SDTA861e (Mettler Toledo, Greifensee, Switzerland) analyzer. The following parameters were applied to perform DMA measurements: temperature range of -100 to $70^{\circ} \mathrm{C}$, heating rate $3{ }^{\circ} \mathrm{C} / \mathrm{min}$, frequency $1 \mathrm{~Hz}$, strain amplitude $4 \mu \mathrm{m}$.

The hardness was measured by Zwick Roell 3105 (Ulm, Germany) hardness tester for disc-shaped samples of the vulcanizates according to the standard ISO 868 [41].

The standard procedure described in the ISO 188 [42] was used to perform the thermooxidative aging of SBR vulcanizates. Following this procedure, plates of the vulcanizates were stored in a drying chamber (Binder, Tuttlingen, Germany) at a temperature of $100{ }^{\circ} \mathrm{C}$ for 7 days. To evaluate the resistance of the vulcanizates to thermo-oxidation, their crosslink density, mechanical properties and hardness after the aging procedure were investigated and compared with the properties of non-aged samples. The aging coefficient $(A F)$ was calculated according to Equation (3) [43] to quantify the resistance of SBR vulcanizates to thermo-oxidation, where TS is the tensile strength of vulcanizates and $E B$ is the elongation at break.

$$
A F=\frac{(E B \times T S)_{\text {after aging }}}{(E B \times T S)_{\text {before aging }}}
$$

Scanning electron microscopy (SEM) images of the vulcanizates were taken using a HITACHI S-4700 (Hitachi, Mannheim, Germany) SEM microscope. Prior to the measurements, the fractures of the vulcanizates were coated with a thin layer of carbon and next examined. Energy-dispersive-X-ray (EDS) spectroscopy was employed to investigate the dispersion of the filler and curatives (sulfur, $\mathrm{ZnO}$, zinc complexes) particles in the elastomer matrix.

The effect of vulcanization activators on the thermal stability of SBR vulcanizates was explored using thermogravimetry (TG) with a TGA/DSC1 (Mettler Toledo, Greifensee, Switzerland) analyzer. First, vulcanizates were heated in the temperature range of $25-600{ }^{\circ} \mathrm{C}$ in an argon atmosphere to examine the pyrolysis of elastomer and organic additives. Then, argon was changed into air and heating was continued up to $900{ }^{\circ} \mathrm{C}$. The heating rate used was $20^{\circ} \mathrm{C} / \mathrm{min}$, whereas the flow rate of gases during TG measurements were $40 \mathrm{~mL} / \mathrm{min}$. The same measurement procedure was applied to study the thermal stability of pure zinc complexes with 1,3-diketones.

\section{Results and Discussion}

\subsection{The Effect of Vulcanization Activators on the Cure Characteristics and Crosslink Density of SBR Elastomer}

The content of zinc is known to affect the efficiency of activator in the vulcanization process and consequently the cure characteristics of rubber compounds [13,24]. As listed in Table 2, zinc complexes with 1,3-diketones contain significantly lower content of zinc compared to $\mathrm{M}-\mathrm{ZnO}$. Thus, they are expected to alter the vulcanization parameters of SBR compounds. The cure characteristics of SBR compounds containing different vulcanization activators are presented in Table 3.

The minimum torque $\left(S_{\min }\right)$ during rheometric test is considered as a measure of the viscosity of the uncrosslinked rubber compound. As expected, no influence of the vulcanization activators on the $S_{\min }$ was observed, so as expected the reduction of zinc in SBR compounds did not alter their viscosity and consequently their processing at $160^{\circ} \mathrm{C}$. Regarding the cure characteristics of rubber compounds, the torque increase $(\Delta S)$ during rheometric measurement is important parameter, since it corresponds to the crosslinking degree of the elastomer. The reference rubber compound with $5 \mathrm{phr}$ of $\mathrm{M}-\mathrm{ZnO}$ was characterized by the torque increase of $16 \mathrm{dNm}$. Despite lower content of the vulcanization activator ( $3 \mathrm{phr}$ ) and consequently the lower content of zinc, application of $\mathrm{N}-\mathrm{ZnO}$ did not 
affect the $\triangle S$ of SBR compounds compared to M-ZnO. Consequently, the crosslink density of the SBR vulcanizates containing $\mathrm{M}-\mathrm{ZnO}$ and $\mathrm{N}-\mathrm{ZnO}$ was almost the same. Moreover, applying $\mathrm{N}-\mathrm{ZnO}$, despite lower content of zinc, did not influence the optimal vulcanization time of SBR compounds compared to $\mathrm{M}-\mathrm{ZnO}$. Thus, it was concluded that $\mathrm{N}-\mathrm{ZnO}$ due to the higher specific surface area and lower particle size exhibited higher activity in the vulcanization than commercially used M-ZnO. Zinc complexes with 1,3-diketones showed lower vulcanization activity than both zinc oxides. It resulted from by approximately 80 $90 \%$ smaller content of zinc compared to elastomer composites with $\mathrm{ZnO}$. The most active zinc complex was HeBPP-Zn, so the one with the heptyl chain in the structure. HeBPP-Zn allowed to obtain significantly higher $\Delta S$ and thus, crosslink density of the vulcanizate compared to other zinc complexes, although $\Delta S$ of SBR compound with HeBPP-Zn was approximately $3 \mathrm{dNm}$ lower compared to rubber compounds with zinc oxides. In addition, HeBPP-Zn did not significantly alter the $\mathrm{t}_{90}$ of SBR compounds as compared to M-ZnO and N-ZnO. SBR compounds with zinc complexes containing methoxy groups (MBPP-Zn, tBuMBPP-Zn and MMBPP-Zn) demonstrated approximately $6 \mathrm{dNm}$ less $\Delta S$ than rubber compounds with $\mathrm{M}-\mathrm{ZnO}$ due to the lower crosslinking degree of the elastomer. It was confirmed by the lower crosslink density of the vulcanizates containing these activators. Thus, zinc complexes with methoxy groups exhibited lower activity in the vulcanization than zinc oxides and HeBPP-Zn. On the other hand, SBR compounds with these zinc complexes showed approximately $50 \%$ shorter $t_{90}$ compared to the rubber compound with $\mathrm{M}-\mathrm{ZnO}$, accompanied with the shorter scorch time $\left(\mathrm{t}_{02}\right)$. It is worth noting that the use of a zinc complex with a methoxy group (MBPP-Zn) as a mixture (1:1) with N-ZnO improved the effectiveness of the vulcanization activator compared to pure zinc complex. As a result, SBR crosslinked with N-ZnO/MBPP-Zn as activator showed the $\Delta S$ and crosslink density similar to the one containing HeBPP-Zn, although still lower compared to $\mathrm{M}-\mathrm{ZnO}$ or pure $\mathrm{N}-\mathrm{ZnO}$. The lower effectiveness of zinc complexes with 1,3-diketones as activators compared to $\mathrm{M}-\mathrm{ZnO}$ was due to the lower content of zinc ions, which are essential for the activation of vulcanization. However, no less important than the content seems to be the availability of the zinc ions in the complex to interact with the curing system (sulfur and accelerator). Thus, despite the highest content of zinc, tBuMBPP-Zn complex in which the access to zinc ions is hindered by the presence of four phenyl rings linked to methoxy groups or t-butyl substituents (Figure 2) showed much lower activity than HeBPP-Zn (Figure 4), in which the availability of zinc ions seems to be the highest among the complexes used.

Table 3. Cure characteristics at $160^{\circ} \mathrm{C}$ and crosslink density of SBR composites containing $\mathrm{ZnO}$ and zinc complexes with 1,3-diketones as activators $\left(S_{\text {min }}\right.$, minimum torque; $\Delta S$, torque increase; $\mathrm{t}_{02}$, scorch time; $\mathrm{t}_{90}$, optimal vulcanization time; $v_{\mathbf{t}}$, crosslink density; $\mathrm{SD}: S_{\min } \pm 0.1 \mathrm{MPa} ; \Delta \leq 2.0 \mathrm{MPa}$; $\mathrm{t}_{02} \pm 0.1$ min.; $\mathrm{t}_{90} \pm 0.3$ min.; $v_{\mathrm{t}} \pm 0.2 \times 10^{-5}$ mole $\left./ \mathrm{cm}^{3}\right)$.

\begin{tabular}{cccccc}
\hline SBR Compounds & $\begin{array}{c}\boldsymbol{S}_{\text {min }} \\
(\mathbf{d N m})\end{array}$ & $\begin{array}{c}\Delta \boldsymbol{S} \\
(\mathbf{d N m})\end{array}$ & $\begin{array}{c}\mathbf{t}_{\mathbf{0 2}} \\
(\mathbf{m i n})\end{array}$ & $\begin{array}{c}\mathbf{t}_{\mathbf{9 0}} \\
(\mathbf{m i n})\end{array}$ & $\begin{array}{c}\mathbf{v}_{\mathbf{t}} \cdot \mathbf{1 0}^{-\mathbf{5}} \\
\left(\mathbf{m o l e} / \mathbf{c m}^{\mathbf{3}}\right)\end{array}$ \\
\hline M-ZnO & 1.1 & 16.0 & 1.0 & 4.7 & 8.9 \\
N-ZnO & 1.1 & 15.8 & 1.4 & 4.8 & 8.8 \\
N-ZnO/MBPP-Zn & 1.1 & 13.5 & 1.1 & 3.7 & 7.8 \\
MBPP-Zn & 1.0 & 9.9 & 0.6 & 2.0 & 6.4 \\
tBuMBPP-Zn & 1.0 & 9.6 & 0.6 & 1.8 & 6.3 \\
MMBPP-Zn & 1.0 & 9.8 & 0.6 & 2.0 & 6.3 \\
HeBPP-Zn & 1.1 & 13.3 & 1.3 & 4.3 & 7.9 \\
\hline
\end{tabular}

Having studied the influence of vulcanization activators and consequently the effect of zinc content reduction on the cure characteristics of SBR compounds, we then established the temperature and enthalpy of curing by DSC analysis. The DSC curves for SBR compounds are presented in Figures 5 and 6, whereas the temperature and enthalpy of curing are summarized in Table 4. 


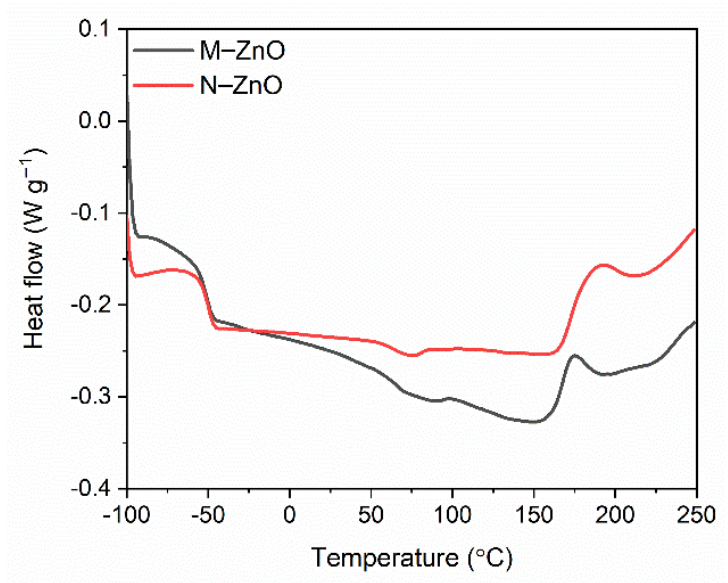

Figure 5. Differential Scanning Calorimetry (DSC) curves of SBR compounds containing M-ZnO and $\mathrm{N}-\mathrm{ZnO}$ as activators.

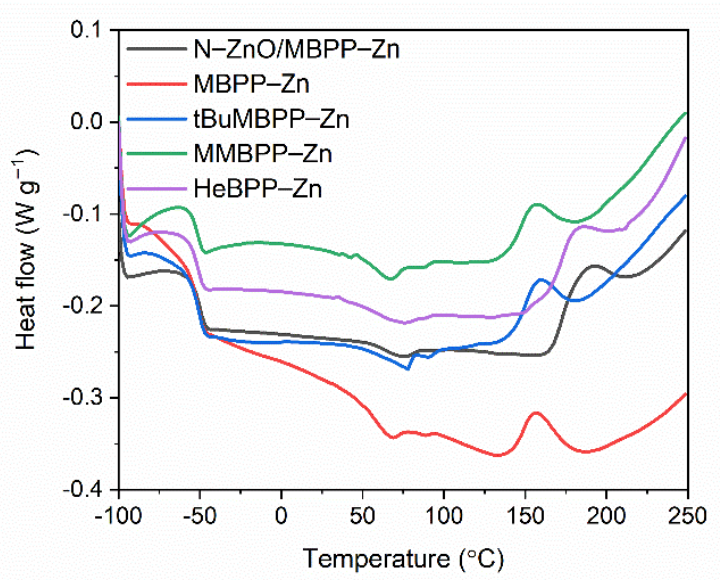

Figure 6. DSC curves of SBR compounds containing zinc complexes with 1,3-diketones as activators.

Analyzing the differential scanning calorimetry (DSC) curves for examined SBR compounds, the first phase transition was observed as a step on the DSC curves due to the glass transition of elastomer. A midpoint of this inflection refers to the glass transition temperature $\left(\mathrm{T}_{\mathrm{g}}\right)$. Despite different content of zinc, SBR elastomers exhibited similar $\mathrm{T}_{\mathrm{g}}$ of approximately $-51^{\circ} \mathrm{C}$.

Table 4. Temperature and enthalpy of curing determined by differential scanning calorimetry (DSC) for SBR compounds containing $\mathrm{ZnO}$ and zinc complexes with 1,3-diketones as activators ( $\mathrm{T}_{\text {cur }}$, curing temperature; $\Delta \mathrm{H}$, curing enthalpy; $\mathrm{T}_{\mathrm{g}}$, glass transition temperature; SD: temperature $\pm 9.0^{\circ} \mathrm{C}$; $\left.\Delta \mathrm{H} \pm 2.6 \mathrm{~J} / \mathrm{g} ; \mathrm{T}_{\mathrm{g}} \pm 1^{\circ} \mathrm{C}\right)$.

\begin{tabular}{cccc}
\hline SBR Compounds & $\begin{array}{c}\mathbf{T}_{\mathbf{c u r}} \\
\left({ }^{\circ} \mathbf{C}\right)\end{array}$ & $\begin{array}{c}\Delta \mathbf{H} \\
(\mathbf{J} / \mathbf{g})\end{array}$ & $\begin{array}{c}\mathbf{T}_{\mathbf{g}} \\
\left({ }^{\circ} \mathbf{C}\right)\end{array}$ \\
\hline M-ZnO & $163-193$ & 7.2 & -51.7 \\
N-ZnO & $165-195$ & 6.8 & -51.8 \\
N-ZnO/MBPP-Zn & $168-206$ & 8.4 & -51.6 \\
MBPP-Zn & $142-177$ & 5.9 & -51.5 \\
tBuMBPP-Zn & $144-178$ & 5.6 & -51.2 \\
MMBPP-Zn & $141-177$ & 5.4 & -51.9 \\
HeBPP-Zn & $166-206$ & 6.4 & -51.7 \\
\hline
\end{tabular}

SBR compound containing $\mathrm{M}-\mathrm{ZnO}$ underwent curing in a temperature range of 163-193 ${ }^{\circ} \mathrm{C}$ with an enthalpy of $7.2 \mathrm{~J} / \mathrm{g}$. It was a one-step process. $\mathrm{N}$-ZnO did not signifi- 
cantly alter the temperature and enthalpy of SBR curing. Regarding zinc complexes with 1,3-diketones, HeBPP-Zn had no considerable influence on the onset curing temperature compared to SBR compound with $\mathrm{M}-\mathrm{ZnO}$, but increased the endset curing temperature from 193 to $206^{\circ} \mathrm{C}$. Thus, the SBR compound with HeBPP-Zn underwent curing in a wider temperature range than that containing $\mathrm{M}-\mathrm{ZnO}$. The enthalpy of curing for SBR with HeBPP-Zn was quite similar to the reference SBR compound with $\mathrm{M}-\mathrm{ZnO}$ taking into account the measurement error. A mixture of activators, i.e., $\mathrm{N}-\mathrm{ZnO}$ and MBPP-Zn, had an analogical to HeBPP-Zn impact on the curing temperature. Applying zinc complexes with methoxy groups reduced both, the onset and the endset curing temperature by approximately $20^{\circ} \mathrm{C}$ compared to zinc oxides and HeBPP-Zn. In addition, SBR compounds with these zinc complexes exhibited lower enthalpies of curing as compared to other activators, so the vulcanization process seemed to be less intensive. Thus, it was concluded that despite of curing temperature reduction, zinc complexes with methoxy groups decreased the efficiency of curing leading to the formation of lower amount of crosslinks in the elastomer network, which was confirmed by the lower crosslink density of the vulcanizates containing zinc complexes with methoxy groups. It was probably due to lower content and availability of zinc ions, which is crucial for activating the vulcanization [24,25].

FTIR spectroscopy was employed to study the influence of vulcanization activators on the structure of SBR vulcanizates. We intended to establish if the type of vulcanization activator, i.e., $\mathrm{ZnO}$ or zinc complex with 1,3-diketone, affected the structure of crosslinked elastomer network. Thus, FTIR spectra of pure SBR rubber and SBR vulcanizates were collected and presented in Figure 7.

The FTIR spectrum of the pure SBR presented in Figure 7a is consistent with the FTIR spectrum reported for this rubber by other researchers [44]. Some absorption bands corresponding to characteristic groups of SBR were observed at the following wavenumber: 2915 and $2843 \mathrm{~cm}^{-1}$ (stretching of $\mathrm{C}-\mathrm{H}$ groups in the aromatic ring of styrene); 1695 and $1639 \mathrm{~cm}^{-1}$ (vibrational of stretches in $\mathrm{CH}_{2}$ and $\mathrm{CH}_{3}$ groups), and $1493 \mathrm{~cm}^{-1}(\mathrm{C}=\mathrm{C}$ aromatic). In addition, the following characteristic for SBR bands were obtained at: 699, 758,910 and $964 \mathrm{~cm}^{-1}$, which resulted from C-H out of plane deformation vibration of monosubstituted benzene, cis-1,4-butadiene and 1,2-butadiene units as well as trans-1,4butadiene of polybutadiene chain segments, respectively $[45,46]$.

Regarding the spectra collected for SBR vulcanizates cured with zinc oxides or zinc complexes as activators, only the bands characteristic for SBR were observed accompanied with a high intensity band at the wavenumber of approximately $490 \mathrm{~cm}^{-1}$, which correspond to $\mathrm{Zn}$ from $\mathrm{ZnO}$ or zinc complex. The type of vulcanization activator did not significantly affect the FTIR spectra of the vulcanizates since the spectra for the tested vulcanizates almost overlapped. Thus, it was concluded that replacing $\mathrm{ZnO}$ with zinc complexes did not considerably influence the structure of the crosslinked elastomer network. However, it should be mentioned that FTIR spectroscopy is not the most accurate and unambiguous method to establish the influence of the activator type on the structure of the elastomer network and the course and mechanism of the crosslinking reaction especially directly in the elastomer matrix, so using the vulcanizates. Therefore, to confirm this conclusion, other, more accurate methods should be used, such as X-ray photoelectron spectroscopy (XPS), time-of-flight secondary ion mass spectrometry (TOF-SIMS) or nuclear magnetic resonance spectroscopy (NMR), the effectiveness of which has been confirmed, for example, in the case of examining the influence of ionic liquids on the EPDM vulcanization mechanism [47]. It would also be worth conducting the research using the model compound vulcanization approach (MCV), replacing the highly viscous elastomeric medium with a liquid, low-molecular model of a fragment of the elastomer chain, e.g., 2,3dimethyl-2-butene, squalene or dibutyl phthalate. MCV is a useful technique for studying the mechanism of accelerated sulfur vulcanization. The effectiveness of this approach in studying the influence of activators on the course of the crosslinking reaction and the structure of the elastomer network has been confirmed by many researchers [48-51]. Moreover, the density functional study proposed by Maity and Pinçák [52] could be helpful to explore 
the interfacial properties of the crosslinking system components. It is useful method to perform a systematic study of the adsorption energy of metal atom, e.g., zinc atom from vulcanization activator, with other curatives, e.g., sulfur.

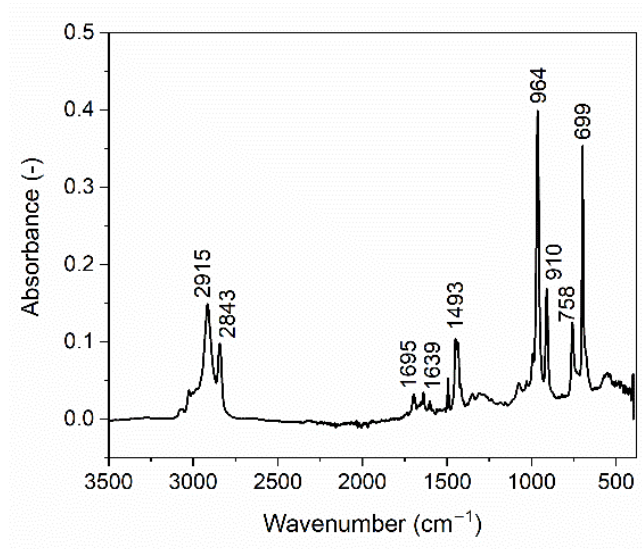

(a)

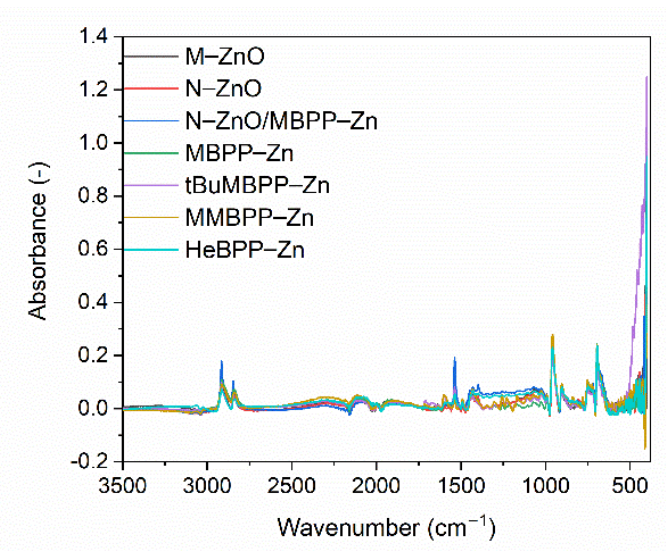

(b)

Figure 7. Fourier Transform Infrared (FTIR) spectra of: (a) pure SBR rubber; (b) SBR vulcanizates containing ZnO and zinc complexes with 1,3-diketones as activators.

\subsection{The Effect of Vulcanization Activators on Tensile Properties and Hardness of SBR Vulcanizates}

Having known that vulcanization activators and consequently reduction of zinc content affected the crosslink density of SBR vulcanizates, we then establish their tensile properties and hardness. These properties are known to be strongly dependent on the crosslink density of the vulcanizates $[53,54]$. The results are presented in Table 5 .

The first parameter shown in Table 5 is the stress at a relative elongation of $300 \%$ $\left(\mathrm{SE}_{300}\right)$, which depends on the crosslink density of the vulcanizate and increases with the number of crosslinks in the elastomer network. Replacing $5 \mathrm{phr}$ of $\mathrm{M}-\mathrm{ZnO}$ with $3 \mathrm{phr}$ of $\mathrm{N}-\mathrm{ZnO}$ did not have a significant influence on $\mathrm{SE}_{300}$ due to the similar crosslink density of the vulcanizates containing each of $\mathrm{ZnO}$. Since reduced crosslink density, vulcanizates with zinc complexes, especially those containing methoxy groups, exhibited significantly lower $\mathrm{SE}_{300}$ compared to SBR cured with zinc oxides. The changes in the $\mathrm{SE}_{300}$ modulus of the vulcanizates strongly correlated with changes in their crosslink density. Thus, among the vulcanizates with zinc complexes, the highest $\mathrm{SE}_{300}$ was shown by that with HeBPP-Zn and the smallest by those with complexes containing methoxy groups.

Table 5. Tensile properties and hardness of SBR compounds containing $\mathrm{ZnO}$ and zinc complexes with 1,3-diketones as activators.

\begin{tabular}{ccccc}
\hline SBR Vulcanizate & $\begin{array}{c}\text { SE }_{\mathbf{3 0 0}} \\
\mathbf{( M P a )}\end{array}$ & $\begin{array}{c}\text { TS } \\
\mathbf{( M P a )}\end{array}$ & $\begin{array}{c}\text { EB } \\
\mathbf{( \% )}\end{array}$ & $\begin{array}{c}\text { H } \\
\text { (ShA) }\end{array}$ \\
\hline M-ZnO & $9.0 \pm 0.1$ & $14.1 \pm 1.4$ & $413 \pm 28$ & $54 \pm 1$ \\
N-ZnO & $8.6 \pm 0.2$ & $16.1 \pm 0.9$ & $458 \pm 15$ & $53 \pm 1$ \\
N-ZnO/MBPP-Zn & $7.0 \pm 0.1$ & $16.4 \pm 1.8$ & $543 \pm 30$ & $52 \pm 1$ \\
MBPP-Zn & $5.4 \pm 0.1$ & $19.9 \pm 1.1$ & $559 \pm 18$ & $46 \pm 1$ \\
tBuMBPP-Zn & $5.4 \pm 0.1$ & $19.5 \pm 1.6$ & $516 \pm 15$ & $46 \pm 1$ \\
MMBPP-Zn & $5.5 \pm 0.1$ & $17.2 \pm 1.5$ & $572 \pm 8$ & $47 \pm 1$ \\
HeBPP-Zn & $7.3 \pm 0.1$ & $15.7 \pm 1.9$ & $507 \pm 17$ & $52 \pm 1$ \\
\hline
\end{tabular}

Similar to $\mathrm{SE}_{300}$, the type of vulcanization activator had an impact on the tensile strength (TS) of SBR vulcanizates. The TS of the reference vulcanizate cured with M$\mathrm{ZnO}$ was $14.1 \mathrm{MPa}$. Despite lower amount of zinc, application of $\mathrm{N}-\mathrm{ZnO}$ enhanced the TS by approximately $2 \mathrm{MPa}$ compared to the benchmark with M-ZnO. Similar TS was 
demonstrated by the vulcanizate containing a mixture of activators, i.e., $\mathrm{N}-\mathrm{ZnO}$ and MBPP$\mathrm{Zn}$. Zinc complexes with 1,3-diketones improved the TS compared to SBR vulcanizates with $\mathrm{M}-\mathrm{ZnO}$ and N-ZnO. The only exception was the vulcanizate cured with HeBPP-Zn, which exhibited TS similar to that containing N-ZnO. The highest TS of approximately $20 \mathrm{MPa}$ was demonstrated by the vulcanizates with MBPP-Zn and tBuMBPP-Zn. Most importantly, despite lower content of zinc and consequently lower crosslink density, vulcanizates containing zinc complexes exhibited enhanced TS in comparison with SBR containing zinc oxides as activators. This could be due to the more homogeneous dispersion of the curatives in the crosslinked elastomer matrix. It is commonly known that the dispersion degree of both the filler particles and the crosslinking system particles, i.e., sulfur, vulcanization activators and accelerators, affects the mechanical properties of the vulcanizates [25]. Thus, SEM/EDS analysis was employed to study the dispersion of the filler and crosslinking system components in the SBR elastomer matrix. SEM images of the selected vulcanizates with EDS maps are presented in Figures 8-10. The analysis was performed for the selected vulcanizates, i.e., those containing $\mathrm{M}-\mathrm{ZnO}, \mathrm{N}-\mathrm{ZnO}$ or zinc complex MBPP-Zn.

An interesting observation was made by analyzing the SEM image and EDS maps of the vulcanizate containing $5 \mathrm{phr}$ of $\mathrm{M}-\mathrm{ZnO}$ (Figure 8). The EDS maps of $\mathrm{Zn}$ and S revealed that the microsized agglomerates, which could be seen in the SEM image, consisted of zinc sulfide (ZnS) formed as a by-product of the sulfur vulcanization. Thus, the use of $5 \mathrm{phr} \mathrm{ZnO}$ resulted in the formation of a significant amount of $\mathrm{ZnS}$ which showed the ability to agglomerate in the elastomer matrix. Consequently, deterioration in the mechanical properties of the vulcanizates was achieved since the agglomerates acted as stress concentration centers when the sample was subjected to external stress [32]. Carbon black (CB) used as a filler was quite homogeneously distributed in the elastomer matrix.

Analyzing SEM image of the vulcanizate containing $3 \mathrm{phr}$ of $\mathrm{N}-\mathrm{ZnO}$ (Figure 9), some microsized agglomerates heterogeneously dispersed in the elastomer matrix were observed, but EDS maps revealed that these agglomerates rather consisted of the CB particles, whereas $\mathrm{Zn}$ and $\mathrm{S}$ were quite uniformly distributed in the elastomer matrix and $\mathrm{ZnS}$ agglomeration did not occur. It was probably due to $40 \%$ lower content of $\mathrm{N}-\mathrm{ZnO}$ compared to $\mathrm{M}-\mathrm{ZnO}$ and consequently lower content of $\mathrm{Zn}$, thanks to which less $\mathrm{ZnS}$ was formed during the vulcanization.

It should be noted that $\mathrm{CB}$ and curatives particles were the most homogeneously distributed in the SBR matrix crosslinked in the presence of zinc complex MBPP-Zn as an activator (Figure 10). Even though CB particles tended to agglomerate (Figure 10b), the resulting agglomerates were smaller in size and more uniformly dispersed in the elastomer matrix compared to the other vulcanizates. The EDS maps of S and Zn (Figure 10d,e) revealed a homogeneous dispersion of these components, and thus the vulcanization activator, in the elastomer. Due to the significantly lower content of $\mathrm{Zn}$ in the MBPP-Zn complex compared to $\mathrm{M}-\mathrm{ZnO}$, a very low amount of $\mathrm{ZnS}$ was formed during the vulcanization and thus, no agglomeration of $\mathrm{ZnS}$ in the elastomer matrix was seen. The homogeneous distribution of the solid additives in the SBR matrix crosslinked in the presence of MBPP-Zn resulted in the significantly increased tensile strength of the vulcanizate as compared to those containing $\mathrm{M}-\mathrm{ZnO}$ or $\mathrm{N}-\mathrm{ZnO}$.

Using $\mathrm{N}-\mathrm{ZnO}$ alternatively to commercially used $\mathrm{M}-\mathrm{ZnO}$ did not have a meaningful effect on the vulcanizates flexibility. The reference vulcanizate with $\mathrm{M}-\mathrm{ZnO}$ showed an elongation at break of $413 \%$, whereas $\mathrm{EB}$ of the vulcanizates cured with $\mathrm{N}-\mathrm{ZnO}$ was $458 \%$. Owing to the lower number of crosslinks in the elastomer network, SBR cured with zinc complexes demonstrated higher EB, which was in the range of $507-572 \%$. As expected, the highest EB manifested vulcanizates with the lowest crosslink density, i.e., those containing zinc complexes with methoxy groups.

$\mathrm{N}-\mathrm{ZnO}$ and its mixture with MBPP-Zn did not significantly alter the hardness of the SBR vulcanizates compared with the reference sample cured with $\mathrm{M}-\mathrm{ZnO}$, which showed the hardness of $54 \mathrm{ShA}$. Vulcanizates with zinc complexes demonstrated the hardness in the 
range of 46-52 ShA. As expected, the lowest hardness was determined for the vulcanizates containing zinc complexes with methoxy groups due to the lowest crosslink density.

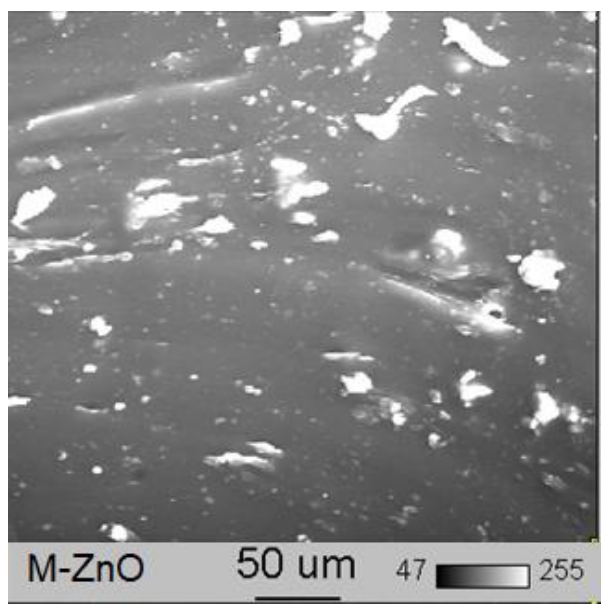

(a)

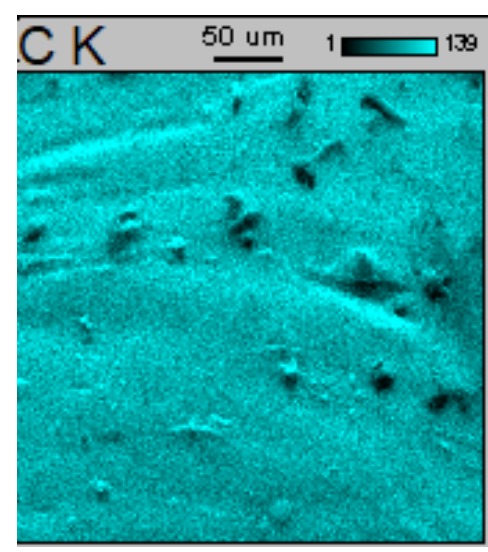

(b)

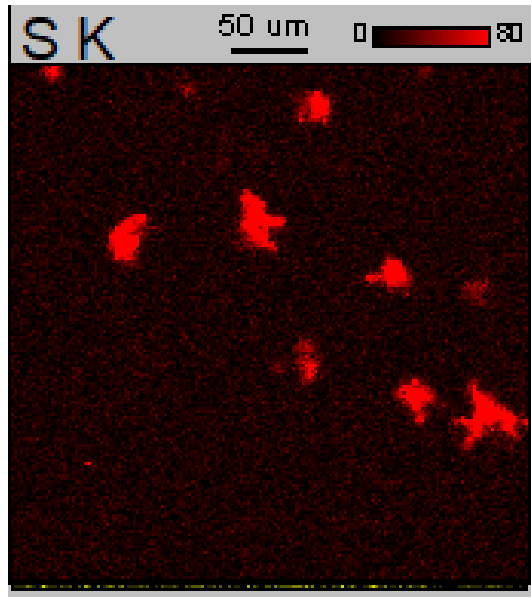

(d)

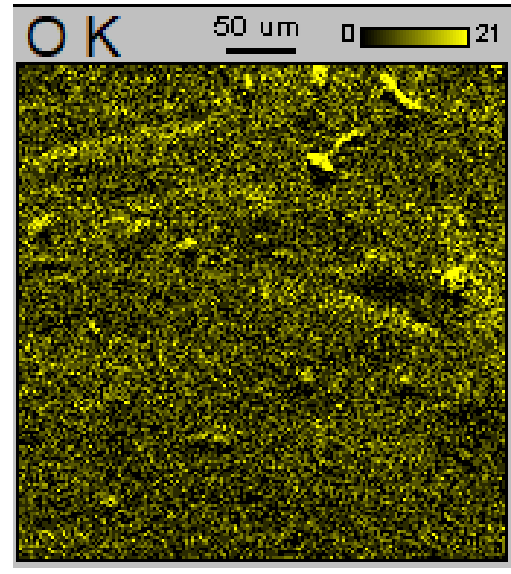

(c)

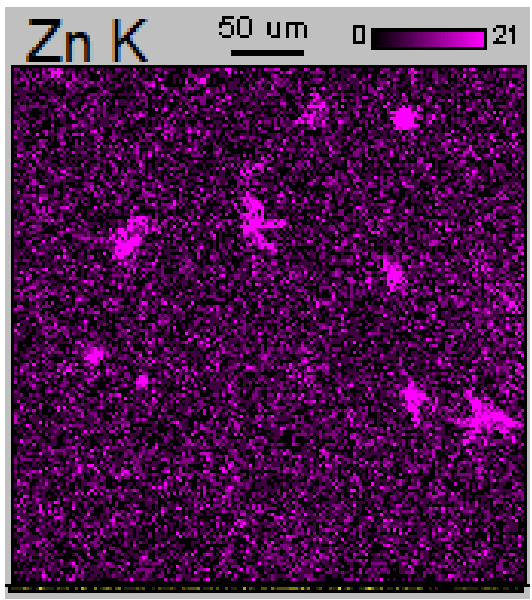

(e)

Figure 8. Scanning electron microscopy (SEM) image and Energy-dispersive X-ray spectroscopy (EDS) maps for SBR vulcanizate containing M-ZnO: (a) SEM image; (b) EDS map for C; (c) EDS map for O; (d) EDS map for S; (e) EDS map for $\mathrm{Zn}$. 


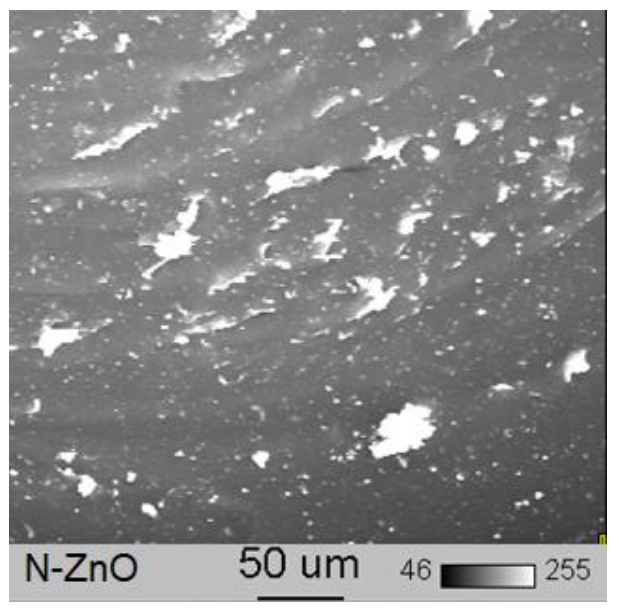

(a)

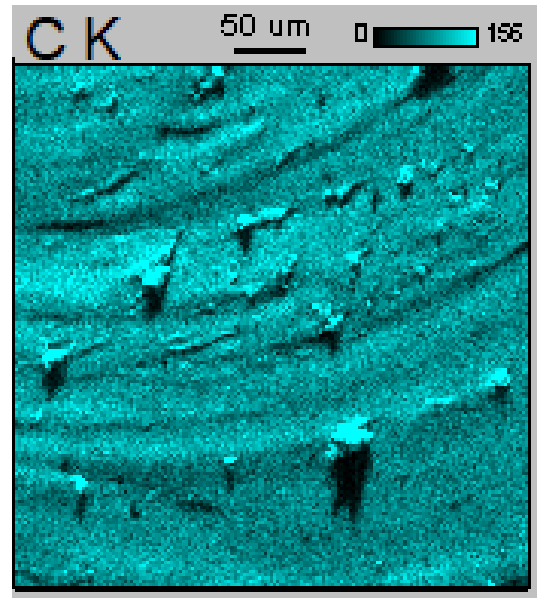

(b)

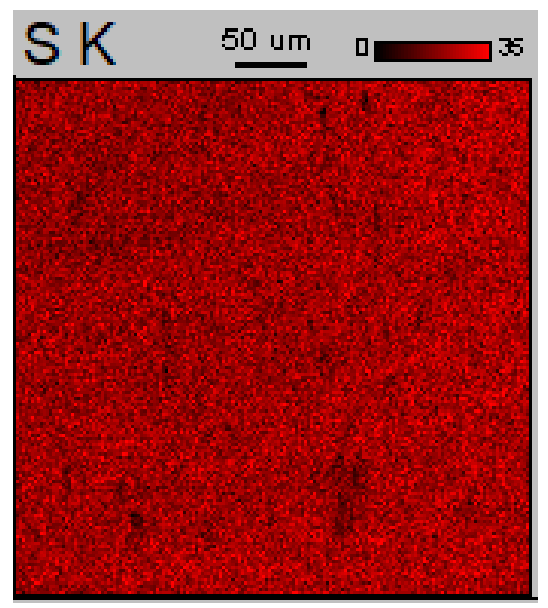

(d)

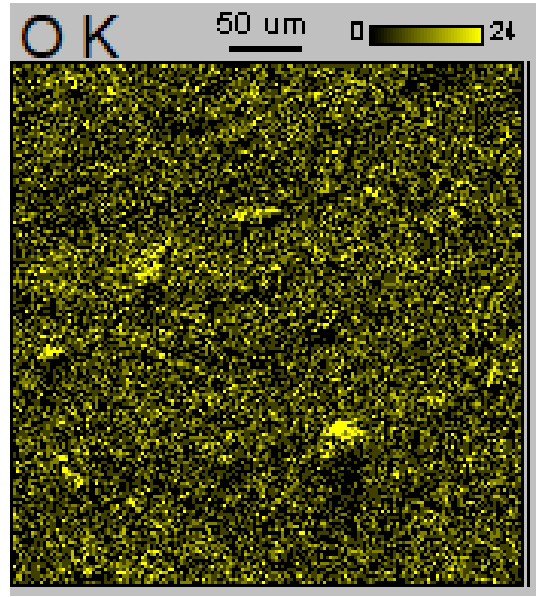

(c)

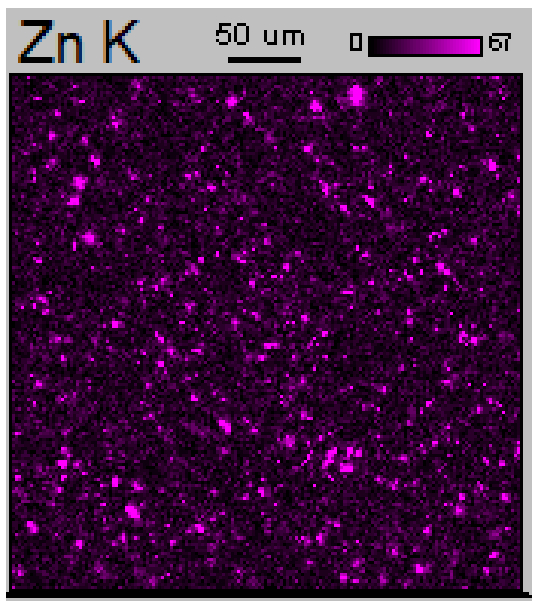

(e)

Figure 9. SEM image and EDS maps for SBR vulcanizate containing N-ZnO: (a) SEM image; (b) EDS map for C; (c) EDS map for O; (d) EDS map for S; (e) EDS map for Zn. 


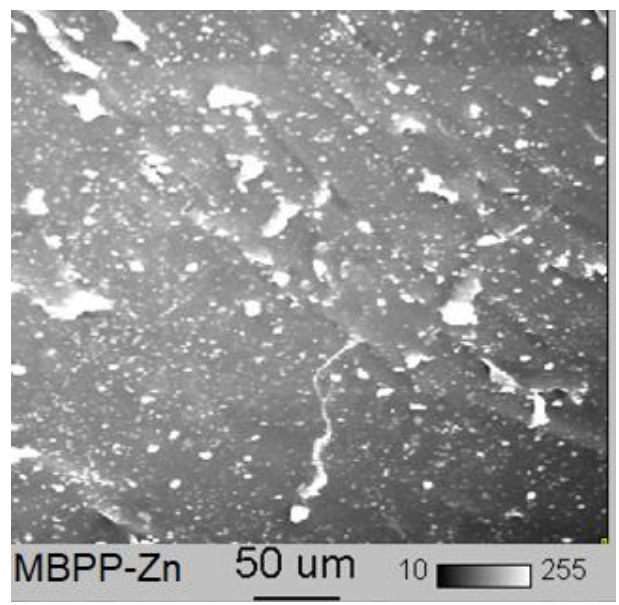

(a)

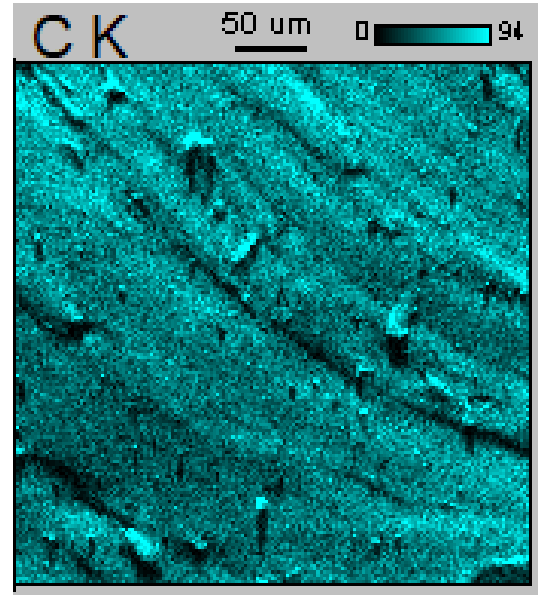

(b)

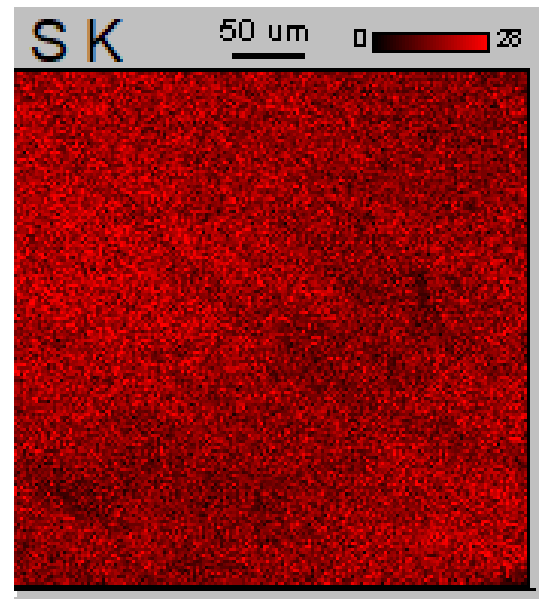

(d)

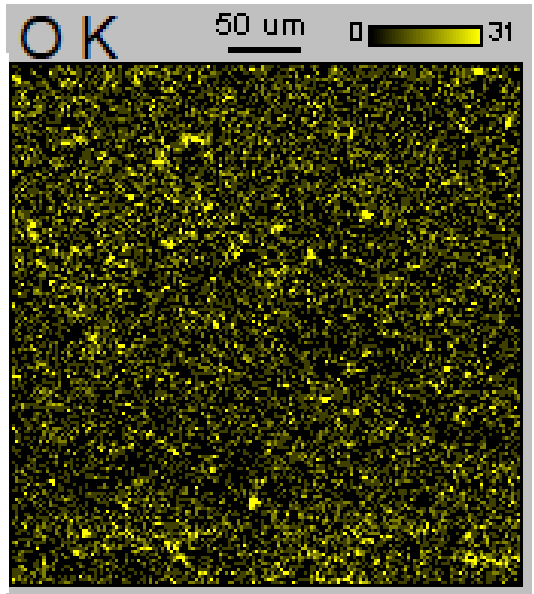

(c)

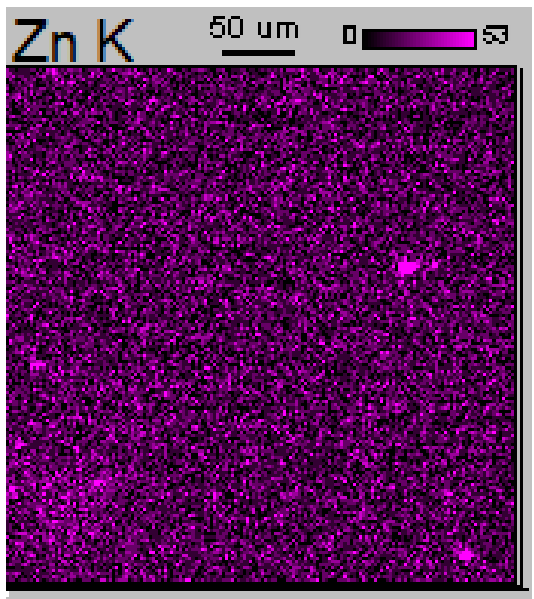

(e)

Figure 10. SEM image and EDS maps for SBR vulcanizate containing MBPP-Zn: (a) SEM image; (b) EDS map for C; (c) EDS map for S; (d) EDS map for Zn.

Most importantly, zinc complexes with 1,3-diketones, despite the approximately $90 \%$ lower content of zinc, allowed to obtain the vulcanizates with improved tensile strength, 
without significantly altering their flexibility and hardness compared to SBR elastomer cured with $\mathrm{M}-\mathrm{ZnO}$.

\subsection{The Effect of Vulcanization Activators on Dynamic Mechanical Properties of SBR Vulcanizates}

Elastomers often operate under conditions of variable deformation, and one of their main applications is vibration damping. Hence, apart from tensile properties, the mechanical performance of the vulcanizates under dynamic conditions is also important for potential applications of rubber products. Dynamic mechanical analysis (DMA) was employed to establish the influence of vulcanization activators with different content of zinc on the viscoelastic properties of SBR vulcanizates, and above all their ability to dampen vibrations. Thus, measurements of mechanical loss factor $(\tan \Delta)$ as a function of temperature were performed. DMA curves of SBR vulcanizates containing different vulcanization activators are presented in Figure 11 and the results are summarized in Table 6.

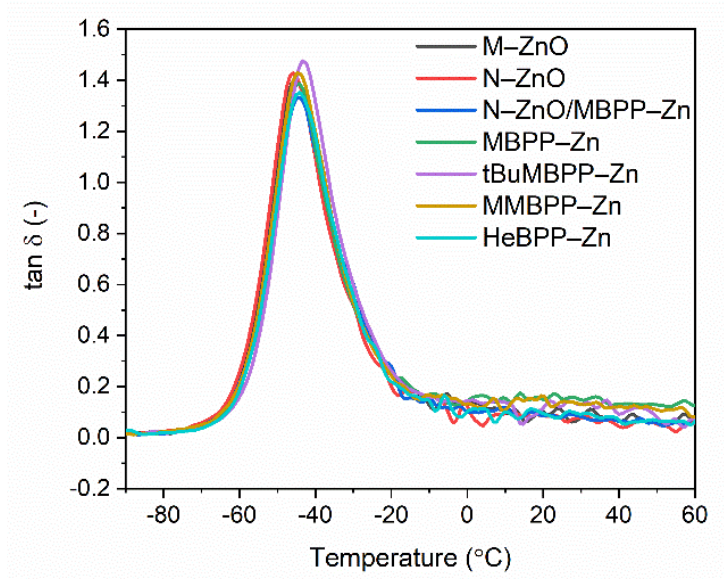

Figure 11. Loss factor $(\tan \Delta)$ curves versus temperature of SBR vulcanizates containing $\mathrm{ZnO}$ and zinc complexes with 1,3-diketones as activators.

Table 6. Glass transition temperature $\left(\mathrm{T}_{\mathrm{g}}\right)$ determined by dynamic mechanical analysis (DMA) and mechanical loss factor $(\tan \delta)$ of SBR vulcanizates containing $\mathrm{ZnO}$ and zinc complexes with 1,3-diketones as activators (SD: $\mathrm{T}_{\mathrm{g}} \pm 1.3{ }^{\circ} \mathrm{C} ; \tan \delta_{\mathrm{Tg}} \pm 0.3 ; \tan \delta_{25-60}{ }^{\circ} \mathrm{C} \pm 0.01$ ).

\begin{tabular}{ccccc}
\hline SBR Vulcanizates & $\begin{array}{c}\mathbf{T}_{\mathbf{g}} \\
\left({ }^{\circ} \mathbf{C}\right)\end{array}$ & $\begin{array}{c}\tan \delta_{\mathbf{T g}} \\
(-)\end{array}$ & $\begin{array}{c}\tan \delta_{25^{\circ} \mathbf{C}} \\
(-)\end{array}$ & $\begin{array}{c}\tan \boldsymbol{\delta}_{60}{ }^{\circ} \mathbf{C} \\
(-)\end{array}$ \\
\hline M-ZnO & -45.5 & 1.40 & 0.10 & 0.07 \\
N-ZnO & -45.8 & 1.43 & 0.08 & 0.06 \\
N-ZnO/MBPP-Zn & -44.2 & 1.33 & 0.08 & 0.08 \\
MBPP-Zn & -44.2 & 1.39 & 0.15 & 0.12 \\
tBuMBPP-Zn & -43.4 & 1.48 & 0.13 & 0.10 \\
MMBPP-Zn & -44.7 & 1.43 & 0.14 & 0.10 \\
HeBPP-Zn & -44.1 & 1.35 & 0.09 & 0.07 \\
\hline
\end{tabular}

The results of DMA analysis listed in Table 6 confirmed that applying $\mathrm{N}-\mathrm{ZnO}$ alternatively to $\mathrm{M}-\mathrm{ZnO}$ did not significantly alter the glass transition temperature $\left(\mathrm{T}_{\mathrm{g}}\right)$ of SBR elastomer, which was of approximately $-45^{\circ} \mathrm{C}$. Considering the experimental error, zinc complexes had no meaningful influence on the $\mathrm{T}_{\mathrm{g}}$ of SBR elastomers, which ranged from -43.4 to $-44.7^{\circ} \mathrm{C}$.

Analyzing the height of the $\tan \delta$ peak $\left(\tan \delta_{\mathrm{Tg}}\right.$ ) on DMA curve, the values of $\tan$ $\delta$ at $T_{g}$ were similar for most of the tested vulcanizates and varied within the range of measurement error. Thus, it was concluded that N-ZnO, MBPP-Zn and MMBPP-Zn did not affect the height of $\tan \delta$ peak. On the other hand, vulcanizates with HeBPP-Zn and with a mixture of $\mathrm{N}-\mathrm{ZnO}$ and MBPP-Zn exhibited only slightly lower $\tan \delta_{\mathrm{Tg}}$ compared to SBR 
cured with zinc oxides, so it is difficult to interpret this as a deterioration of the elastomer ability to dampen vibrations. Regarding the values of $\tan \delta$ at 25 and $60^{\circ} \mathrm{C}$, i.e., in the elastic region, $\mathrm{N}-\mathrm{ZnO}$ and its mixture with MBPP-Zn, as well as HeBPP-Zn had no meaningful influence on the damping properties of SBR elastomer. Furthermore, it was observed that vulcanizates containing zinc complexes with methoxy groups exhibited higher $\tan \delta$ in the elastic region compared to other vulcanizates. Thus, they should demonstrate better damping properties in the elastic state compared to SBR cured with commercially used $\mathrm{M}-\mathrm{ZnO}$. Most importantly, despite significantly lower content of zinc in rubber compounds, applying $\mathrm{N}-\mathrm{ZnO}$ and zinc complexes with 1,3-diketones alternatively to $\mathrm{M}-\mathrm{ZnO}$ did not deteriorate the ability of SBR elastomer to dampen vibrations.

\subsection{The Effect of Vulcanization Activators on Resistence of SBR Vulcanizates to Thermo-Oxidative Aging}

Rubber products are commonly used in outdoor applications; therefore, they are subject to long-term exposure to external factors causing their aging and, consequently, deterioration of functional properties. One of these factors is long-term thermo-oxidation. Therefore, the influence of alternative vulcanization activators, i.e., $\mathrm{N}-\mathrm{ZnO}$ and zinc complexes with 1,3-diketones, on the resistance of SBR to thermo-oxidative aging was investigated. SBR vulcanizates were stored at $100{ }^{\circ} \mathrm{C}$ for 7 days, and then their crosslink density, mechanical performance and hardness were determined and compared with those of non-aged vulcanizates. The influence of thermo-oxidative aging on the properties of SBR vulcanizates is presented in Figure 12.

Prolonged exposure to thermo-oxidation significantly enhanced the crosslink density of SBR vulcanizates, especially those containing $\mathrm{M}-\mathrm{ZnO}$ and $\mathrm{N}-\mathrm{ZnO}$ as activators (Figure 12a). The increase in the crosslink density after thermo-oxidative aging is commonly reported for elastomers $[55,56]$. Slightly smallest changes in the crosslink density occurred for the vulcanizates containing a mixture of activators, i.e., $\mathrm{N}-\mathrm{ZnO}$ and MBPP-Zn or HeBPP-Zn. In turn, the lowest increase in the crosslink density (significantly lower than for other vulcanizates) was observed for the vulcanizates with zinc complexes containing methoxy groups, which showed the lowest crosslink density before aging process. It probably resulted from the lower efficiency of zinc complexes having methoxy groups in activating vulcanization. It should be noted that vulcanization of elastomers, similar to most other technological processes, does not run with 100\% efficiency. Vulcanization of rubber compounds at $t_{90}$ as vulcanization time allows for the optimal use of the curatives under given conditions, which does not mean that they are completely consumed. Consequently, some unreacted crosslinkers remain inside the elastomer matrix and prolonged exposure to elevated temperature may initiate further crosslinking reactions resulting in additional crosslinks in the "aged" elastomer network. The results discussed earlier revealed that zinc complexes with methoxy groups were less active in vulcanization, therefore their ability to activate vulcanization during thermo-oxidative aging was also lower than other activators and hence a smaller increase in the crosslink density of the vulcanizates was achieved during aging. This assumption is also confirmed by the fact that the crosslink density of vulcanizates containing zinc oxides or the most active zinc complex, i.e., HeBPP-Zn, increased much more as a result of aging than that of SBR with less active zinc complexes.

Since hardness depends on the crosslink density, regardless of the vulcanization activator used, vulcanizates after thermo-oxidative aging exhibited by approximately 6-9 ShA higher hardness compared to the non-aged samples (Figure 12b). The highest hardness after thermo-oxidation was demonstrated by the vulcanizates containing $\mathrm{M}-\mathrm{ZnO}$ (63 ShA) and $\mathrm{N}-\mathrm{ZnO}$ (61 ShA), respectively.

Owing to the higher crosslink density, vulcanizates exhibited significantly higher modulus at $100 \%$ relative elongation $\left(\mathrm{SE}_{100}\right)$ after aging process (Figure 12c). As expected, the highest enhancement of $\mathrm{SE}_{100}$ (by approximately $2 \mathrm{MPa}$ ) was demonstrated by the vulcanizates with the highest crosslink density, so those containing $\mathrm{M}-\mathrm{ZnO}, \mathrm{N}-\mathrm{ZnO}$ and HeBPP-Zn. Vulcanizates with zinc complexes having methoxy groups demonstrated 
smaller changes in $\mathrm{SE}_{100}$ upon thermo-oxidation (reduction by 1.0-1.3 MPa compared to non-aged samples).

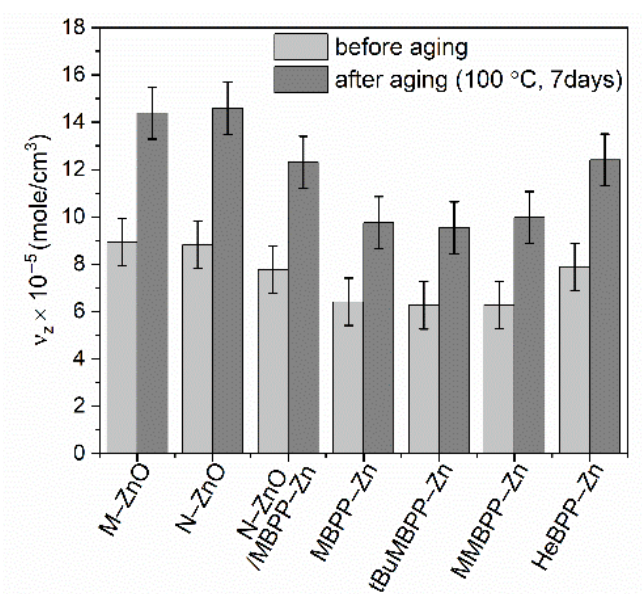

(a)

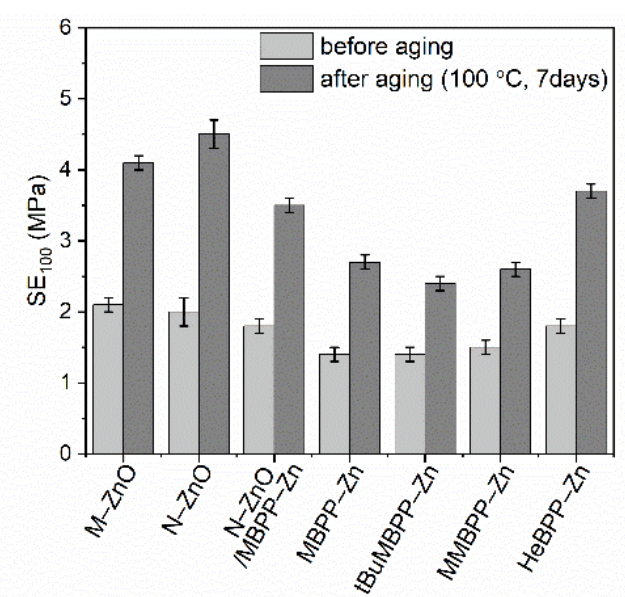

(c)

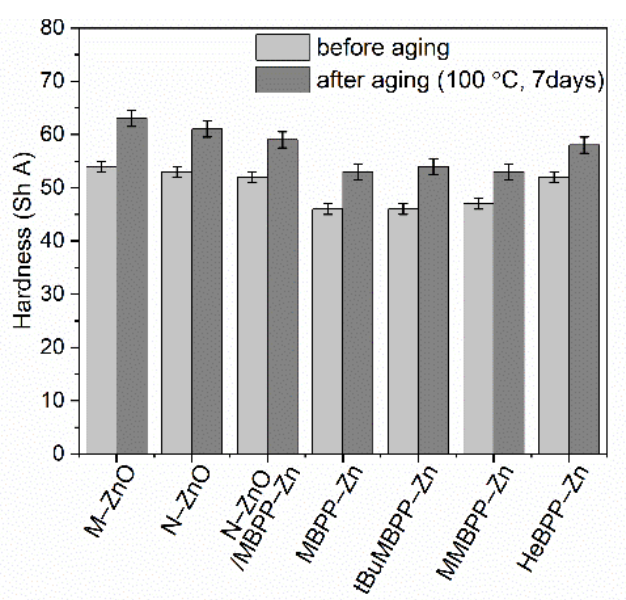

(b)

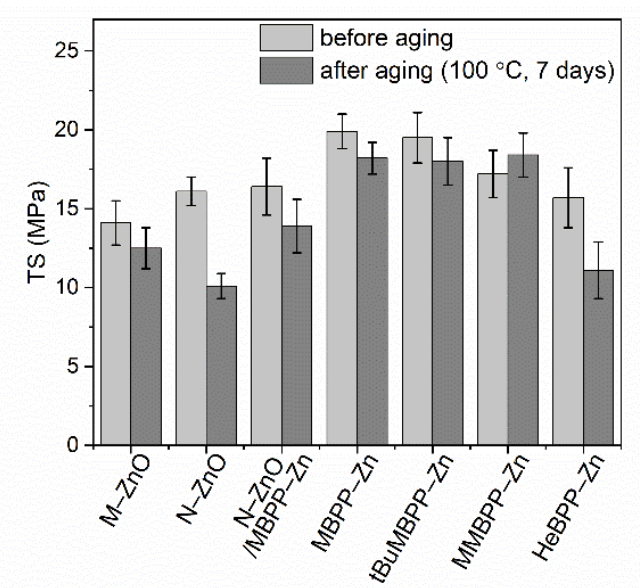

(d)

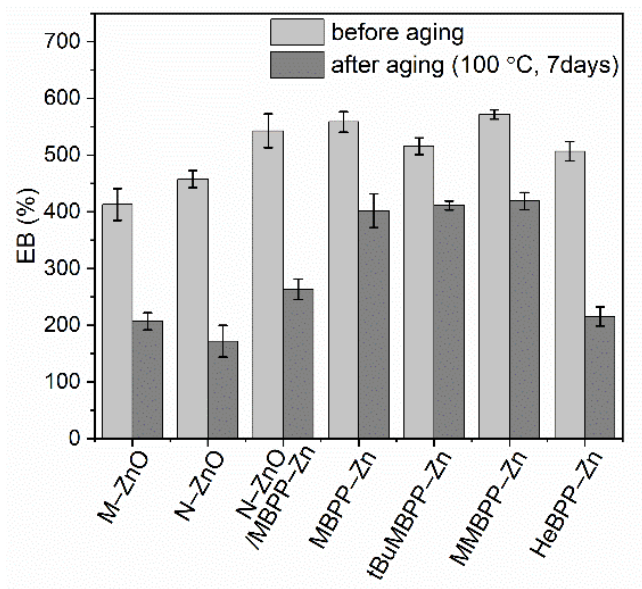

(e)

Figure 12. The influence of prolonged thermo-oxidation on the properties and crosslink density of SBR vulcanizates containing $\mathrm{ZnO}$ and zinc complexes with 1,3-diketones as activators: (a) crosslink density; (b) hardness; (c) stress at 100\% relative elongation; (d) tensile strength; (e) elongation at break. 
Regardless of the activator used, prolonged thermo-oxidation deteriorated the tensile strength (TS) of SBR vulcanizates. TS of the reference vulcanizate with $\mathrm{M}-\mathrm{ZnO}$ was reduced by approximately $2 \mathrm{MPa}$ (Figure 12d), whereas for $\mathrm{N}-\mathrm{ZnO}$ containing vulcanizate significantly higher reduction in TS was achieved, i.e., $6 \mathrm{MPa}$. Regarding zinc complexes, the highest decrease in TS was demonstrated by the vulcanizate with HeBPP-Zn. On the other hand, vulcanizates containing zinc complexes with methoxy groups exhibited smaller changes in TS under thermo-oxidative aging, demonstrating TS by approximately $1.5-2.5 \mathrm{MPa}$ lower compared to that of non-aged samples. Thus, it was concluded that SBR crosslinking during the thermo-oxidative aging caused this elastomer to be over-crosslinked, and consequently brittle and more susceptible to mechanical stress. Consequently, lower stress was sufficient to break the sample and its TS was reduced. The relationship between the TS and crosslink density of the elastomers is commonly known [2]. TS rises with the crosslink density of the elastomer to a certain critical value of the crosslink density, above which the elastomer becomes over-crosslinked. Further increasing the crosslink density of the elastomer causes the reduction in TS.

Thermo-oxidative aging significantly affected the elongation at break $(E B)$ of SBR vulcanizates causing it to decrease compared to $E B$ of the non-aged vulcanizates (Figure 12e). This resulted from the increase in the crosslink density under aging. As expected, the higher the increase in crosslink density of the vulcanizates, the greater the reduction in their elongation at break after thermo-oxidative aging was achieved. Thus, the highest reduction in $E B$ by approximately $300 \%$ was observed for the vulcanizates containing $\mathrm{N}-\mathrm{ZnO}$ and its mixture with MBPP-Zn or zinc complex HeBPP-Zn, whereas EB of the reference vulcanizate cured with $\mathrm{M}-\mathrm{ZnO}$ was reduced by approximately $200 \%$ compared to that of the non-aged sample. Significantly smaller changes in $E B$ after aging occurred for SBR containing zinc complexes with methoxy groups, for which $E B$ was reduced by $100-150 \%$.

It is difficult to estimate the resistance of an elastomeric material to aging processes by considering its individual mechanical parameters separately. Further, the aging coefficient $A F$ was determined, which combines changes in individual parameters of the vulcanizates, i.e., $T S$ and $E B$ due to aging, and relates them to the values obtained for non-aged material. Results are presented in Table 7.

Table 7. Thermo-oxidative aging coefficient $(A F)$ of SBR vulcanizates containing $\mathrm{ZnO}$ and zinc complexes with 1,3-diketones as activators (SD: $A F \pm 0.1$ ).

\begin{tabular}{cc}
\hline SBR Vulcanizate & AF (-) \\
\hline M-ZnO & 0.4 \\
N-ZnO & 0.3 \\
N-ZnO/MBPP-Zn & 0.4 \\
MBPP-Zn & 0.7 \\
tBuMBPP-Zn & 0.7 \\
MMBPP-Zn & 0.8 \\
HeBPP-Zn & 0.3 \\
\hline
\end{tabular}

Referring to Equation (3) on the basis of which the aging coefficient $(A F)$ was determined, the closer to 1 the value of $A F$, the greater the resistance of the material to aging, as this process causes less changes in the mechanical properties, i.e., TS and $E B$, of the vulcanizates.

The reference vulcanizate with $\mathrm{M}-\mathrm{ZnO}$ demonstrated $A F$ of approximately 0.4 , so it was highly susceptible to thermo-oxidative aging. Applying N-ZnO and its mixture with MBPP-Zn did not affected the resistance of SBR to long-term thermo-oxidation ( $A F$ was in the range of measurement error). Similar $A F$ was determined for the vulcanizate containing zinc complex HeBPP-Zn.

On the other hand, vulcanizates with zinc complexes containing methoxy groups exhibited significantly improved resistance to thermo-oxidative aging, demonstrating the 
$A F$ in the range of $0.7-0.8$. However, the improvement in aging resistance should not be attributed to the action of the zinc complexes themselves, but rather, as already mentioned, to their lower activity in the crosslinking process. Consequently, the increase in the crosslink density due to thermo-oxidative aging for vulcanizates containing zinc complexes with methoxy substituents was much lower than for other vulcanizates, resulting in less deterioration of their mechanical properties compared to vulcanizates with zinc oxides and HeBPP-Zn.

Most importantly, $\mathrm{N}-\mathrm{ZnO}$ and zinc complexes with 1,3-diketones did not worsen the resistance of SBR to prolonged thermo-oxidation, which is important for their potential technological application as vulcanization activators alternative to $\mathrm{M}-\mathrm{ZnO}$, which enable the significant reduction in the amount of zinc in rubber products.

\subsection{The Effect of Vulcanization Activators on Thermal Stability of SBR Vulcanizates}

Zinc complexes with 1,3-diketones are organic compounds which are expected to decompose when heating to high temperatures. Thermal stability of elastomer composites depends on the thermal behavior of both elastomer matrix and components of the rubber compounds, especially the organic ones. Hence, the effect of zinc complexes on the thermal stability of SBR vulcanizates was investigated using thermogravimetry (TG). The results are shown in Figure 13 and summarized in Table 8.

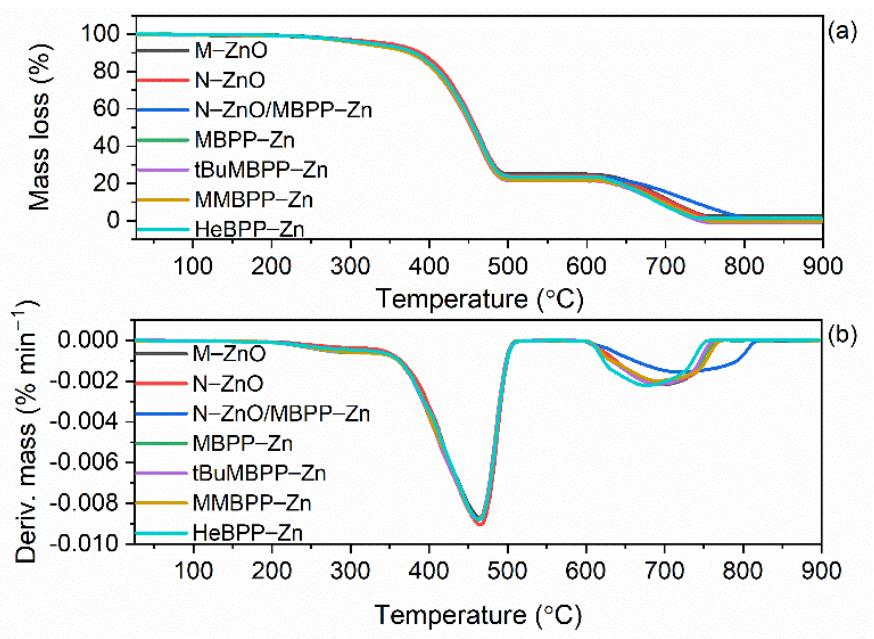

Figure 13. Thermogravimetric (TG) and Derivative Thermogravimetric (DTG) curves of SBR vulcanizates containing $\mathrm{ZnO}$ and zinc complexes with 1,3-diketones as activators: (a) TG curves; (b) DTG curves.

Table 8. Onset temperature of thermal decomposition $\left(\mathrm{T}_{5 \%}\right)$, DTG peak temperature $\left(\mathrm{T}_{\mathrm{DTG}}\right)$ and total mass loss $(\Delta \mathrm{m})$ during decomposition of SBR compounds containing $\mathrm{ZnO}$ and zinc complexes with 1,3-diketones as activators (SD: $\mathrm{T}_{5 \%} \pm 1.1^{\circ} \mathrm{C} ; \mathrm{T}_{\mathrm{DTG}} \pm 1.0^{\circ} \mathrm{C} ; \Delta \mathrm{m} \pm 1.6 \%$ ).

\begin{tabular}{cccccc}
\hline SBR Vulcanizate & $\begin{array}{c}\mathbf{T}_{\mathbf{5} \%} \\
\left({ }^{\circ} \mathbf{C}\right)\end{array}$ & $\begin{array}{c}\mathbf{T}_{\mathbf{D T G}} \\
\left({ }^{\circ} \mathbf{C}\right)\end{array}$ & $\begin{array}{c}\left.\Delta \mathbf{m}_{(\mathbf{2 5 - 6 0 0}}{ }^{\circ} \mathbf{C}\right) \\
(\mathbf{\%})\end{array}$ & $\begin{array}{c}\left.\Delta \mathbf{m}_{(\mathbf{6 0 0 - 9 0 0}}{ }^{\circ} \mathbf{C}\right) \\
\mathbf{( \% )}\end{array}$ & $\begin{array}{c}\text { Residue at } \\
\mathbf{9 0 0}{ }^{\circ} \mathbf{C}(\mathbf{\%})\end{array}$ \\
\hline M-ZnO & 334 & 482 & 73.5 & 22.3 & 4.2 \\
N-ZnO & 346 & 483 & 74.6 & 22.7 & 2.7 \\
N-ZnO/MBPP-Zn & 328 & 480 & 76.4 & 22.3 & 1.3 \\
MBPP-Zn & 310 & 481 & 77.5 & 22.2 & 0.3 \\
tBuMBPP-Zn & 312 & 480 & 77.3 & 22.2 & 0.5 \\
MMBPP-Zn & 313 & 481 & 77.7 & 22.1 & 0.2 \\
HeBPP-Zn & 320 & 481 & 77.4 & 22.2 & 0.4 \\
\hline
\end{tabular}

Analyzing TG and DTG curves presented in Figure 13, two mass losses were achieved for the investigated vulcanizates. The first mass loss occurred in the temperature range 
of $25-600{ }^{\circ} \mathrm{C}$ and it was determined in argon atmosphere. Thus, it corresponds to the pyrolysis of elastomer matrix and organic ingredients such as vulcanization accelerators and zinc complexes with 1,3-diketones. Therefore, vulcanizates containing zinc complexes exhibited higher mass losses in the temperature range of $25-600{ }^{\circ} \mathrm{C}$ than the vulcanizates with zinc oxides (Table 8). In the temperature range of $600-900{ }^{\circ} \mathrm{C}$ argon was replaced by air, so the mass loss observed corresponds mainly to the combustion of carbon black, which was used as a filler, accompanied by the combustion of the residues from the first stage of thermal decomposition. Owing to the same content of filler, the mass loss in the temperature range of $600-900{ }^{\circ} \mathrm{C}$ was similar for all vulcanizates (approximately $22 \%$ ) regardless of the applied vulcanization activator.

The mineral residue after thermal decomposition at $900{ }^{\circ} \mathrm{C}$ depended on the vulcanization activator used and it was the highest (approximately $4.2 \%$ ) for the reference vulcanizate due to the content of $5 \mathrm{phr} \mathrm{M}-\mathrm{ZnO}$, which remained after thermal decomposition. The mineral residue at $900{ }^{\circ} \mathrm{C}$ for the vulcanizate with $\mathrm{N}-\mathrm{ZnO}$ was of approximately $2.7 \%$ and resulted from 3 phr of $\mathrm{N}-\mathrm{ZnO}$. On the other hand, the residue after thermal decomposition of the vulcanizates with zinc complexes consisted of ash and was in the range of $0.2-0.5 \%$ because the organic zinc complexes underwent complete thermal decomposition under the conditions of measurement.

The reference vulcanizate with $\mathrm{M}-\mathrm{ZnO}$ began to thermally decompose at a temperature of approximately $334{ }^{\circ} \mathrm{C}$. $\mathrm{N}$-ZnO increased the onset decomposition temperature $\left(\mathrm{T}_{5 \%}\right)$ of SBR to $346^{\circ} \mathrm{C}$. This may result from the network formed by $\mathrm{ZnO}$ nanoparticles dispersed in the elastomer matrix, which hinders the diffusion of gases and volatile products of thermal decomposition through the composite and thus prevents thermal decomposition [57]. As expected, zinc complexes with 1,3-diketones, especially those containing methoxy groups, deteriorated thermal stability of the vulcanizates. The $\mathrm{T}_{5 \%}$ temperature decreased by approximately $10-14{ }^{\circ} \mathrm{C}$ for the vulcanizates containing zinc complexes with methoxy groups and by $8^{\circ} \mathrm{C}$ for HeBPP-Zn compared to the reference vulcanizate with $\mathrm{M}-\mathrm{ZnO}$. This resulted from the low thermal stability of zinc complexes compared to SBR elastomer matrix as confirmed by TG analysis of pure zinc complexes (Figure 14, Table 9). Zinc complexes with 1,3-diketones demonstrated different thermal stability depending on their structure and were characterized by $\mathrm{T}_{5 \%}$ in the range of $141-249{ }^{\circ} \mathrm{C}$, whereas $\mathrm{T}_{\text {DTG }}$ ranged from 404 to $413^{\circ} \mathrm{C}$ for HeBPP-Zn and tBuMBPP-Zn, respectively. The most thermally stable zinc complex was $t B u M B P P-Z n$, while the lowest $T_{5 \%}$ was determined for HeBPP-Zn probably due to the fragmentation of long heptyl chain, which initiated thermal decomposition of this complex. The thermal decomposition of aliphatic-aromatic compounds with long alkyl substituents was reported to begin with the fragmentation of long alkyl chains [58]. Deterioration of the thermal stability of SBR elastomer by incorporation of organic additives, which decompose at lower temperatures compared to pure SBR was confirmed by Prochon et al. [59].

On the other hand, vulcanization activators did not significantly affect the peak temperature of DTG curve $\left(\mathrm{T}_{\mathrm{DTG}}\right)$ which was in the range of $480-483{ }^{\circ} \mathrm{C}$. Therefore, it was concluded that decomposition of SBR vulcanizates with zinc complexes began at lower temperatures but proceeded at a rate similar to that of the $\mathrm{ZnO}$-containing vulcanizates. Most importantly, regardless of the vulcanization activator applied, SBR vulcanizates were thermally stable up to a temperature of approximately $310^{\circ} \mathrm{C}$, which is sufficient for their technological applications.

Table 9. Thermal stability of zinc complexes with 1,3-diketones $\left(\mathrm{T}_{5 \%}\right.$, decomposition temperature at $5 \%$ of the mass change; $\mathrm{T}_{\mathrm{DTG}}$, DTG peak temperature; standard deviations (SD): $\mathrm{T}_{5 \%}, \mathrm{~T}_{\mathrm{DTG}} \pm 2{ }^{\circ} \mathrm{C}$ ).

\begin{tabular}{ccc}
\hline Zinc Complex & $\mathbf{T}_{\mathbf{5} \%}\left({ }^{\circ} \mathbf{C}\right)$ & $\mathbf{T}_{\text {DTG }}\left({ }^{\circ} \mathbf{C}\right)$ \\
\hline MBPP-Zn & 189 & 405 \\
tBuMBPP-Zn & 249 & 413 \\
MMBPP-Zn & 225 & 408 \\
HeBPP-Zn & 141 & 404 \\
\hline
\end{tabular}




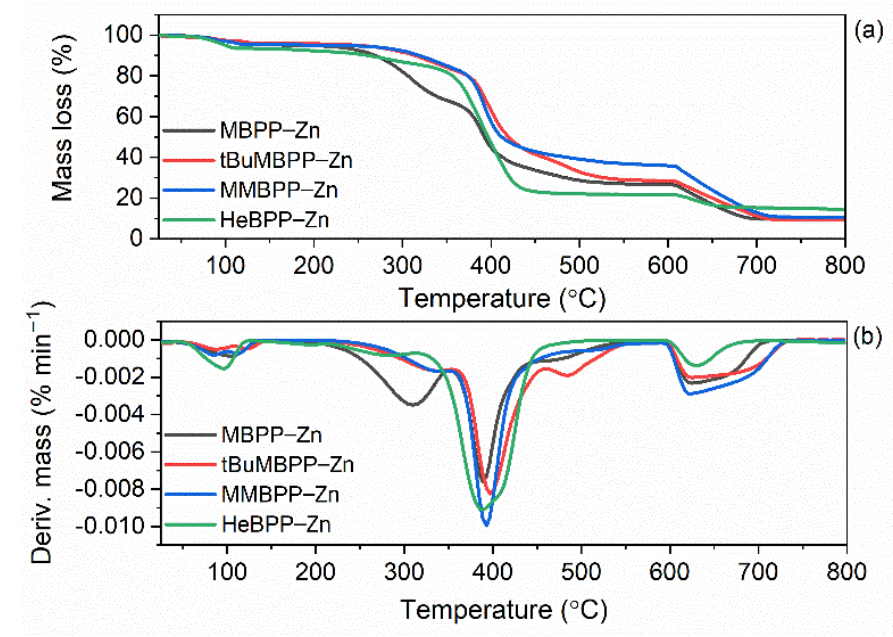

Figure 14. Thermal stability of zinc complexes with 1,3-diketones: (a) TG curves; (b) DTG curves.

\section{Conclusions}

The possibility of zinc amount reduction in SBR composites filled with carbon black was investigated. For this purpose, $\mathrm{N}-\mathrm{ZnO}$ and complexes of zinc with 1,3-diketones were applied as vulcanization activators alternatively to the commercially used $\mathrm{M}-\mathrm{ZnO}$.

Applying $\mathrm{N}-\mathrm{ZnO}$ enabled to reduce the content of zinc by $40 \%$ compared to $\mathrm{M}$ $\mathrm{ZnO}$ without detrimental influence on the cure characteristic of SBR compounds and crosslink density of the vulcanizates. N-ZnO did not significantly affect the resistance of SBR vulcanizates to thermo-oxidative aging and their ability to dampen vibrations. Moreover, vulcanizates with $\mathrm{N}-\mathrm{ZnO}$ exhibited enhanced tensile strength and thermal stability compared to SBR cured with M-ZnO.

Despite the 80-90\% lower zinc content, zinc complexes with 1,3-diketones effectively activated the vulcanization of SBR compounds and their activity depended on the zinc complex structure, i.e., the availability of zinc ions to react with curatives. The highest activity in vulcanization was demonstrated by the zinc complex with two phenyl rings and heptyl chains, i.e., HeBPP-Zn, in which the attainability of zinc was significantly better compared to zinc complexes with diketones having four phenyl rings, methoxy groups and t-butyl chains. Thus, HeBPP-Zn had no significant influence on the time and temperature of rubber compounds vulcanization. Compared to SBR cured with $\mathrm{M}-\mathrm{ZnO}$, vulcanizate with HeBPP-Zn exhibited slightly lower crosslink density, slightly worse damping properties and thermal stability, similar resistance to thermo-oxidative aging and improved tensile strength. Due to the steric hindrance, which hindered the availability of zinc to react with curatives, zinc complexes with four phenyl ring and methoxy groups showed lower activity in the vulcanization, and consequently vulcanizates with these complexes demonstrated lower crosslink density and hardness. However, it should be noted that despite lower content of crosslinks, vulcanizates with MBPP-Zn, tBuMBPP-Zn and MMBPP-Zn exhibited significantly enhanced tensile strength (of approximately $20 \mathrm{MPa}$ ) and resistance to thermooxidative aging, as well as improved damping properties compared to SBR cured with $\mathrm{M}-\mathrm{ZnO}$. In addition, regardless of the vulcanization activators, SBR composites were thermally stable up to a temperature of $310^{\circ} \mathrm{C}$.

Most importantly, performed studies confirmed that zinc complexes with 1,3-diketones can be successfully used as vulcanization activators which allow a 80-90\% reduction in the content of zinc compared to SBR compounds with commercially used M-ZnO. This is important for ecological reasons. Moreover, the lower content of zinc in rubber compounds the lower amount of $\mathrm{ZnS}$ is formed as a by-product of crosslinking reactions. $\mathrm{ZnS}$ is commonly known to stain the vulcanization molds, which makes it necessary to clean them after the vulcanization cycle is completed. Thus, the reduction of zinc is important also for technological reasons. 
Author Contributions: Conceptualization, M.M.; methodology, M.M.; software, A.S. and A.G.; validation, M.M.; formal analysis, M.M., A.S. and A.G.; investigation, A.G.; resources, M.M.; data curation, A.S. and A.G.; writing — original draft preparation, M.M. and A.S.; writing-review and editing, M.M.; visualization, A.S.; supervision, M.M.; project administration, M.M.; funding acquisition, M.M. All authors have read and agreed to the published version of the manuscript.

Funding: This research received no external funding.

Institutional Review Board Statement: Not applicable.

Informed Consent Statement: Not applicable.

Data Availability Statement: The data presented in this study are available on request from the corresponding author.

Conflicts of Interest: The authors declare no conflict of interest.

\section{References}

1. Kruželák, J.; Sýkora, R.; Hudec, I. Vulcanization of rubber compounds with peroxide curing systems. Rubber Chem. Technol. 2017, 90, 60-88. [CrossRef]

2. Coran, A.Y. Chemistry of the vulcanization and protection of elastomers: A review of the achievements. J. Appl. Polym. Sci. 2002, 87, 24-30. [CrossRef]

3. Leroy, E.; Souid, A.; Deterre, R. A continuous kinetic model of rubber vulcanization predicting induction and reversion. Polym. Test. 2013, 32, 575-582. [CrossRef]

4. Milani, G.; Milani, F. Fast and reliable meta-data model for the mechanistic analysis of NR vulcanized with sulphur. Polym. Test. 2014, 33, 64-78. [CrossRef]

5. Mansilla, M.A.; Marzocca, A.J.; Macchi, C.; Somoza, A. Influence of vulcanization temperature on the cure kinetics and on the microstructural properties in natural rubber/styrene-butadiene rubber blends prepared by solution mixing. Eur. Polym. J. 2015, 69, 50-61. [CrossRef]

6. Krejsa, M.R.; Koenig, J.L. A review of sulfur crosslinking fundamentals for accelerated and unaccelerated vulcanization. Rubber Chem. Technol. 1993, 66, 376-410. [CrossRef]

7. Heideman, G.; Datta, R.N.; Noordermeer, J.W.M.; Van Baarle, B. Activators in accelerated sulfur vulcanization. Rubber Chem. Technol. 2004, 77, 512-541. [CrossRef]

8. Kruželák, J.; Sýkora, R.; Hudec, I. Sulphur and peroxide vulcanization of rubber compounds-Overview. Chem. Pap. 2016, 70, 1533-1555. [CrossRef]

9. Ibarra, L.; Marcos-Fernández, A.; Alzorriz, M. Mechanistic approach to the curing of carboxylated nitrile rubber (XNBR) by zinc peroxide/zinc oxide. Polymer 2002, 43, 1649-1655. [CrossRef]

10. Begum, P.M.S.; Yusuff, K.K.M.; Joseph, R. Preparation and use of nano zinc oxide in neoprene rubber. Int. J. Polym. Mater. 2008, 57, 1083-1094. [CrossRef]

11. Owczarek, M.; Zaborski, M. Chlorosulfonated polyethylene elastomers containing zinc oxide incorporated on $\mathrm{SiO}_{2}$. Kaut. Gummi Kunstst. 2004, 57, 218-223.

12. Ebadi-Dehaghani, H.; Reiszadeh, M.; Chavoshi, A.; Nazempour, M.; Vakili, M.H. The effect of zinc oxide and calcium carbonate nanoparticles on the thermal conductivity of polypropylene. J. Macromol. Sci. Part B 2014, 53, 93-107. [CrossRef]

13. Chapman, A.; Johnson, T. The role of zinc in the vulcanization of styrene-butadiene rubbers. Kaut. Gummi Kunstst. 2005, 58, 358-361.

14. Pysklo, L.; Pawlowski, P.; Parasiewicz, W.; Slusarski, L. Study on reduction of zinc oxide level in rubber compounds part I: Influence of zinc oxide specific surface area and the interphase transfer catalyst 18-crown-6. Kaut. Gummi Kunstst. 2007, 60, 548-553.

15. Kim, I.-J.; Kim, W.-S.; Lee, D.-H.; Kim, W.; Bae, J.-W. Effect of nano zinc oxide on the cure characteristics and mechanical properties of the silica-filled natural rubber/butadiene rubber compounds. J. Appl. Polym. Sci. 2010, 117, 1535-1543. [CrossRef]

16. Przybyszewska, M. The effect of zinc oxide nanoparticle morphology on activity in crosslinking of carboxylated nitrile elastomer. Express Polym. Lett. 2009, 3, 542-552. [CrossRef]

17. Anand, A.; Nussana, L.; Aan, M.P.S.; Ekwipoo, K.; Sangashetty, S.G.; Jobish, J. Synthesis and characterization of ZnO nanoparticles and their natural rubber composites. J. Macromol. Sci. Part B 2020, 59, 697-712. [CrossRef]

18. Sahoo, S.; Maiti, M.; Ganguly, A.; George, J.J.; Bhowmick, A.K. Effect of zinc oxide nanoparticles as cure activator on the properties of natural rubber and nitrile rubber. J. Appl. Polym. Sci. 2007, 105, 2407-2415. [CrossRef]

19. Panampilly, B.; Thomas, S. Nano ZnO as cure activator and reinforcing filler in natural rubber. Polym. Eng. Sci. 2013, 53, 1337-1346. [CrossRef]

20. Roy, K.; Alam, N.; Mandal, S.K.; Debnath, S.C. Sol-gel derived nano zinc oxide for the reduction of zinc oxide level in natural rubber compounds. J. Sol Gel Sci. Technol. 2014, 70, 378-384. [CrossRef] 
21. Przybyszewska, M.; Zaborski, M. Effect of ionic liquids and surfactants on zinc oxide nanoparticle activity in crosslinking of acrylonitrile butadiene elastomer. J. Appl. Polym. Sci. 2010, 116, 155-164. [CrossRef]

22. Laskowska, A.; Marzec, A.; Boiteux, G.; Zaborski, M.; Gain, O.; Serghei, A.; Maniukiewicz, W. Improving the ionic conductivity of carboxylated nitrile rubber/LDH composites by adding imidazolium bis(trifluoromethylsulfonyl)imide ionic liquids. Macromol. Symp. 2014, 342, 35-45. [CrossRef]

23. Maciejewska, M.; Sowińska, A. Thermal characterization of the effect of fillers and ionic liquids on the vulcanization and properties of acrylonitrile-butadiene elastomer. J. Therm. Anal. Calorim. 2019, 138, 4359-4373. [CrossRef]

24. Heideman, G.; Noordermeer, J.W.M.; Datta, R.N.; Van Baarle, B. Effect of zinc complexes as activator for sulfur vulcanization in various rubbers. Rubber Chem. Technol. 2005, 78, 245-257. [CrossRef]

25. Helaly, F.; El Sabbagh, S.; El Kinawy, O.; El Sawy, S. Effect of synthesized zinc stearate on the properties of natural rubber vulcanizates in the absence and presence of some fillers. Mater. Des. 2011, 32, 2835-2843. [CrossRef]

26. Maciejewska, M.; Sowińska, A.; Kucharska, J. Organic zinc salts as pro-ecological activators for sulfur vulcanization of styrenebutadiene rubber. Polymers 2019, 11, 1723. [CrossRef] [PubMed]

27. Moresco, S.; Giovanela, M.; Carli, L.; Crespo, J. Development of passenger tire treads: Reduction in zinc content and utilization of a bio-based lubricant. J. Clean. Prod. 2016, 117, 199-206. [CrossRef]

28. Zanchet, A.; De Sousa, F.D.B.; Crespo, J.S.; Scuracchio, C.H. Activator from sugar cane as a green alternative to conventional vulcanization additives. J. Clean. Prod. 2018, 174, 437-446. [CrossRef]

29. Heideman, G.; Noordermeer, J.W.M.; Datta, R.N.; Van Baarle, B. Zinc loaded clay as activator in sulfur vulcanization: A new route for zinc oxide reduction in rubber compounds. Rubber Chem. Technol. 2004, 77, 336-355. [CrossRef]

30. Das, A.; Wang, D.-Y.; Leuteritz, A.; Subramaniam, K.; Greenwell, C.; Wagenknecht, U.; Heinrich, G. Preparation of zinc oxide free, transparent rubber nanocomposites using a layered double hydroxide filler. J. Mater. Chem. 2011, 21, 7194-7200. [CrossRef]

31. Przybyszewska, M. Zinc chelates as new activators for sulphur vulcanization of acrylonitrile-butadiene elastomer. Express Polym. Lett. 2009, 3, 256-266. [CrossRef]

32. El-Gamal, A. Effect of reinforcement filler on vulcanization, diffusion, mechanical, and electrical properties of natural rubber. $J$. Elastomers Plast. 2018, 51, 512-526. [CrossRef]

33. Mukhopadyay, R.; De, S.K. Effect of vulcanization temperature and different fillers on the properties of efficiently vulcanized natural rubber. Rubber Chem. Technol. 1979, 52, 263-277. [CrossRef]

34. Ni, H.-Y.; Wang, S.-W.; Zhou, Y.-J.; Chen, J. The effect of fillers on the vulcanizing performances and mechanical properties of the fluoroelastomer. Polym. Technol. Eng. 2010, 49, 1079-1086. [CrossRef]

35. ISO 6502-3:2018, Rubber-Measurement of Vulcanization Characteristics Using Curemeters-Part 3: Rotorless Rheometer; International Organization for Standardization: Geneva, Switzerland, 2018.

36. ISO 11357-1:2016, Plastics_Differential Scanning Calorimetry (DSC)_Part 1: General Principles; International Organization for Standardization: Geneva, Switzerland, 2016.

37. ISO 1817:2015, Rubber, Vulcanized or Thermoplastic—Determination of Effect of Liquids; International Organization for Standardization: Geneva, Switzerland, 2017.

38. Flory, P.J.; Rehner, J. Statistical mechanics of cross-linked polymer networks II. Swelling. J. Chem. Phys. 1943, 11, 521-526. [CrossRef]

39. Furuta, I.; Kimura, S.; Iwama, M. Physical constants of rubbery polymers. In Polymer Handbook, 4th ed.; Brandrup, J., Immergut, E.H., Grulke, E.A., Eds.; John Wiley and Sons: New York, NY, USA, 1999; pp. 1-7.

40. ISO 37:2017, Rubber, Vulcanized or Thermoplastic-Determination of Tensile Stress-Strain Properties; International Organization for Standardization: Geneva, Switzerland, 2017.

41. ISO 868:2003, Plastics and Ebonite-Determination of Indentation Hardness by Means of a Durometer (Shore Hardness); International Organization for Standardization: Geneva, Switzerland, 2003.

42. ISO 188:2011, Rubber, Vulcanized or Thermoplastic-Accelerated Ageing and Heat Resistance Tests; International Organization for Standardization: Geneva, Switzerland, 2011.

43. Masłowski, M.; Miedzianowska, J.; Czylkowska, A.; Efenberger-Szmechtyk, M.; Nowak, A.; Strzelec, K. Anti-oxidative activity of alcohol-water extracts from field horsetail (Equisteum arvense) in elastomer vulcanizates subjected to accelerated aging processes. Materials 2020, 13, 4903. [CrossRef]

44. Guo, L.; Huang, G.; Zheng, J.; Li, G. Thermal oxidative degradation of styrene-butadiene rubber (SBR) studied by 2D correlation analysis and kinetic analysis. J. Therm. Anal. Calorim. 2014, 115, 647-657. [CrossRef]

45. He, S.; Bai, F.; Liu, S.; Ma, H.; Hu, J.; Chen, L.; Lin, J.; Wei, G.; Du, X. Aging properties of styrene-butadiene rubber nanocomposites filled with carbon black and rectorite. Polym. Test. 2017, 64, 92-100. [CrossRef]

46. Luna, C.B.B.; Araújo, E.M.; Siqueira, D.D.; Morais, D.D.D.S.; Filho, E.A.D.S.; Fook, M.V.L. Incorporation of a recycled rubber compound from the shoe industry in polystyrene: Effect of SBS compatibilizer content. J. Elastomers Plast. 2019, 52, 3-28. [CrossRef]

47. Sowińska, A.; Maciejewska, M.; Guo, L.; Delebecq, E. Task-specific ionic liquids with lactate anion applied to improve ZnO dispersibility in the ethylene-propylene-diene elastomer. Polymers 2021, 13, 774. [CrossRef] 
48. Boretti, L.G.; Woolard, C.D. An appropriate model compound for the accelerated sulfur vulcanization of polyisoprene: I. The mechanism of bisbenzothiazole-2,2'-disulfide accelerated vulcanization of squalene in the absence of ZnO. Rubber Chem. Technol. 2006, 79, 135-151. [CrossRef]

49. Damen, R.; Nieuwenhuizen, P.J.; Haasnoot, J.G.; Reedijk, J.; Couchman, S.M.; Jeffery, J.; McCleverty, J.A. Homogeneous zinc (II) catalysis in accelerated vulcanization: V. The prevailing mechanism of crosslink formation in mercaptobenzothiazole systems. Rubber Chem. Technol. 2003, 76, 82-100. [CrossRef]

50. Shumane, M.; Gradwell, M.H.S.; McGill, W.J. Dimethylammonium dimethyldithiocarbamate-accelerated sulfur vulcanization. II. Vulcanization of rubbers and model compound 2,3-dimethyl-2-butene. J. Appl. Polym. Sci. 2001, 82, 3074-3083. [CrossRef]

51. Morgan, B.; McGill, W.J. Benzothiazole-accelerated sulfur vulcanization. V. 2-bisbenzothiazole-2,2'-disulfide/ZnO and 2bisbenzothiazole-2,2'-disulfide/(2-mercaptobenzothiazole)zinc(ii) as accelerators for 2,3-dimethyl-2-butene. J. Appl. Polym. Sci. 2000, 76, 1413-1421. [CrossRef]

52. Maity, A.; Pinčák, R. Density functional study of blue phosphorene-metal interface. Eur. Phys. J. B 2021, 94, 1-11. [CrossRef]

53. Gronski, W.; Hoffmann, U.; Simon, G.; Wutzler, A.; Straube, E. Structure and density of crosslinks in natural-rubber vulcanizates. A combined analysis by NMR spectroscopy, mechanical measurements, and rubber-elastic theory. Rubber Chem. Technol. 1992, 65, 63-77. [CrossRef]

54. Zhao, F.; Bi, W.; Zhao, S. Influence of crosslink density on mechanical properties of natural rubber vulcanizates. J. Macromol. Sci. Part B 2011, 50, 1460-1469. [CrossRef]

55. Masłowski, M.; Miedzianowska, J.; Strzelec, K. Natural rubber composites filled with crop residues as an alternative to vulcanizates with common fillers. Polymers 2019, 11, 972. [CrossRef]

56. Kruželák, J.; Dosoudil, R.; Hudec, I. Thermooxidative aging of rubber composites based on NR and NBR with incorporated strontium ferrite. J. Elastomers Plast. 2018, 50, 71-91. [CrossRef]

57. Chae, D.W.; Kim, B.C. Effects of zinc oxide nanoparticles on the physical properties of polyacrylonitrile. J. Appl. Polym. Sci. 2005, 99, 1854-1858. [CrossRef]

58. Sowińska, A.; Maciejewska, M.; Guo, L.; Delebecq, E. Thermal analysis and SEM microscopy applied to studying the efficiency of ionic liquid immobilization on solid supports. Materials 2019, 12, 1579. [CrossRef] [PubMed]

59. Prochoń, M.; Janowska, G.; Przepiórkowska, A.; Kucharska-Jastrzabek, A. Thermal properties and combustibility of elastomerprotein composites. J. Therm. Anal. Calorim. 2011, 109, 1563-1570. [CrossRef] 